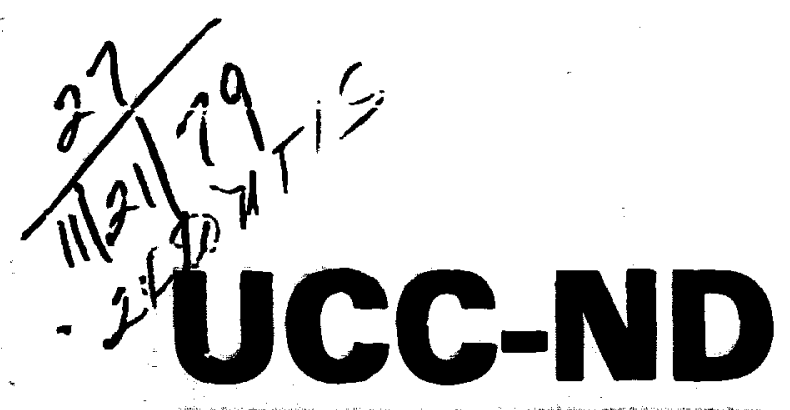

ORNL/CSD/TM-94

NUCLEAR

DIVISION

unION
EARBIDE

\title{
MASTER
}

\section{TORCAPP: Time-Dependent Cyclotron Orbit Calculation and Plotting Package}

\author{
Linda B. Maddax \\ Gregory S. McNeiily
}


ORNL/CSD/TH-94

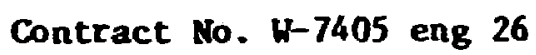

Computer Sciences Division

\section{TORCAPP: Time-Dependent Cyclotron Orbit Calculation and Plotting Package}

Linda B. Maddox

Gregory S. McNeilly

Sponsor: J. B. Ball

Originator: Linda B. Maddox

Work supported by

Holifield Heavy Ion Research Eacility, Physics Division

Date Published - November 1979

UNION CARBIDE CORPORATION, NUCLEAR DIVISION operating the

Dak Ridge Gaseous Dirfusion Plant - Oak Ridge National Laboratory Oak Ridge Y-12 Plant

- Paducah Gaseous Diffusion Plant

for the

DEPARTMENT OF ENERCY

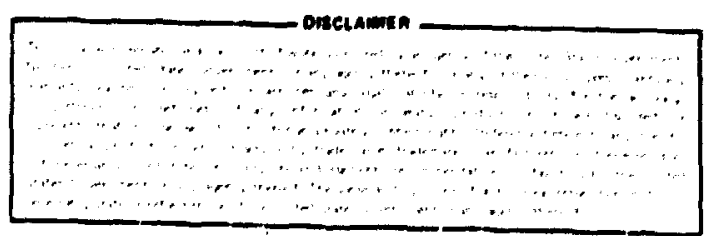


LIST OF FIGURES ACKIIOW . FDCAENTS ABSTRACT

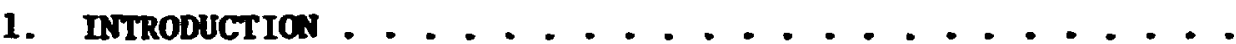

2. CAPABILITIES AND FUNCTIONS ..............

Calculations Performed in CAIPAT . . . . . . . .

Printed Output from CALPAT and PATPLT. . . . . . . .

Plots Generated from PATPLT. . . . . . . . . . . . 6

3. GERERAL EQUATIONS THPLELETTED. . . . . . . . . . . 7

Equations of Motion in an Electronagnetic Field. . . . 7

Determination of $x, y$, and $z$ Components of the Hagnetic

Field . . - . . . .

Page

Interpolation to get Field Value at the Desired Point

B $(x, y, 0)$.

Two-Point Central Differenting used in Calculating

Partial Derivatives of the magnetic Field . . .

Calculation of Transverse Distances and Homenta for

Packet Plots. . . . . . . . . . . . . . . . 9

Runge-Kutta I: tegration. . . . . . . . . . . . . 10

4. DESCRIPTION OE SUBROUTINES .............. 11

CALPAT - . . . . . . . . . . . . . . . . . . . . . 11

1. MATN . . . . . . . . . . . . . . . . . . . 11

2. INPUTF . . +. . . . . . . . . . . . . . . 11

3. INPUTP . . . . . . . . . . . . . . . . . 11

4. PACKET . . . . . . . . . . . . . . . . . 11

5. FPHI . . . . . . . . . . . . . . . . . . . 11

6. PARTCL ......................... 11

7. DE.......................... 12

8. EQUA - . . . . . . . . . . . . . . . . . . . 12

צ. BRECT. . . . . . . . . . . . . . . . . . . 12

10. BINTRP . . . . . . . . . . . . . . . . . . 12

11. BPRTME . . . . . . . . . . . . . . . . . . 12

PATPLT . . . . . . . . . . . . . . . . . . . . 12

1. MAD ....................... 12

2. PLOTNL . . . . . . . . . . . . . . . . . 13

3. Plot1P . . . . . . . . . . . . . . . . . 13

4. PLTPAK . . . . . . . . . . . . . . . . . 14

5. DATA IMPUT GUIDE .................. 15

CALPAT - Init 5. . . . . . . . . . . . . . . . . 15

1. Plotting varlables Pormat (6I5). . . . . . . . 15

2. Calculatton type variables Format (3I5)...... 15

3. Field size variables Format (4I5). . . . . . . . 15

4. Field step sizes and accuracy parameters

Format (4F10.0) . . . . . . . . . . . . . 15

5. Tleld format Format (18A4)............. 15

6. Isuchrontzing factorg Pormat (8P10.0). . . . . . 16

7. Packet wdths and phase space areas

Format (4E10.5) .............. 16 

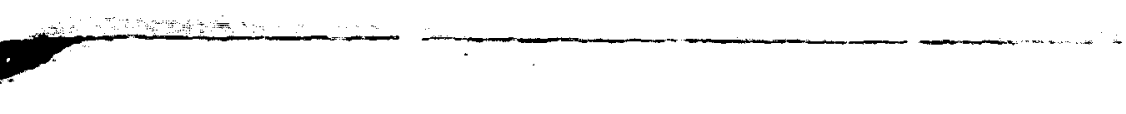

4

BLANK PAGE 
8. Particle and integration variables

Pornat (6El0.5) ............... 16

9. Time-plotting variables Format (E15.6, 15, E15.6).. 16

10. Tuber of particles and interpolation nesh-size adjustor Porwat (I5, F10.0) .......... 16

11. Particle position variables Fornat (F10.2, I5, F10.2, 2E15.6). . . . . . . . . . . 17

12. Particle position variables Format (3E15.6/3E15.6). - 17 CAIPA- - Onit 10. . . . . . . . . . . . 18

1. Field data Format $[72 x$ (FTI) ] ........... 18

PATPLT - Uaft 11. ................ 19

1. Plotting variables Pornat (8I5, 3F5.0). ...... 19

2. Plotting variebles Pornat (1515).......... 19

Input Vartable Definitions. . . . . . . . . . . 20

6. PLOTIIIC PROCEDURE. . . . . . . . . . . . . . 25

7. EXIYIE JCL ..................... 27

SAYPLF JCL FOR DECUTITG CALPAT ............. 27

SAYPLE JCL TO EASCUIE CALCOAP POSTPROCESSOR ........ 29

SAYPLE JCL TO SEID COAPRESSED DATA TO PDP-10 DISK ARRA. . . 30

SAYPLE JCL FOR EXECUTTUG PATPLT . . . . . . . . . 31

8. EXHYPLE CALCULATIOAS. . . . . . . . . . . . . 33

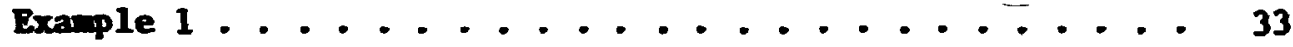

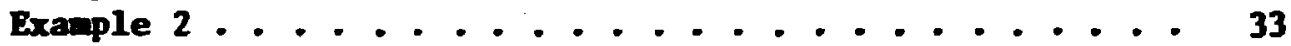

Example 3 ................. 33

9. UIITS IRTORHATIOA .................. 41

APPEAIIX A. . . . . . . . . . . . . . . . . 4 ?

RETEREICES. . . . . . . . . . . . . . . . . 47 


\section{LIST OR FIGURES}

Fig. 8.1. IKPUT DATA SET POR SIMLLE PARTICLE INJECTION . - - 34

Fig - 8.2. STIGLE PARTICLE INJECTIOA. . . . . . . . . . 35

Fig- 8.3. ITPUT DATA SET FOR RINE PARTICLE PACKET InJECTIOA. - 36

Fig. 8.4. ITIE PARTICLE PACKET MUJECTIOA . . . . . . . . . 37

Fig. 8.5. IRTUT DATA SET FOR PRECESSTOAAL THJECTION. . . . . 39

Fig. 8.6. Precessional InJECTIOA . . . . . . . . . 40

Fig. A.1. PHASE SPACE PACKET . . . . . . . . . . . 44

Fig. A.2. Transpocuhation TC Transterse PLANE ....... 45 


\section{AckROMLEDGERTS}

The authors gratefully acknowledge the assistance of $\mathrm{J}$. D. Bell in dehugging portions of the packet calculation.

The development and documentation of this progran were funded by Holffield Heavy Ion Research Facility, Phvsics Division, under Contract No. W-7405 eng 26. 
TORCAPP: Time-Dependen: Cyclotron Orbit Calculation and Plotting Package

Linda B. Maddox

Gregory S. Mcleilly

\section{ABSTRACT}

TORCAPP calculates the motion of charged particles in elcctromagnetic fields with time as the independent variablc, and produces a variety or printed and plotted output of results. Finite-size beam behavi.vr is studied conveniently by following groups of particles which otíine an appropriate phase space area. Since time is the independent variable, general wotion in the nearmedian-plane region may ise followed. This includes, for example, loops not enclosing the origin and strongly radial wotions. Thus, TORCAPP is particularly useful for injection studies for isochronous cyclotrons, or other devices with near-median-plane charged particle motion. 


\section{INTRODUCTION}

TORCAPP (Time-dependent cyclotron orbit calculation and plotting package) consists of two prograns, one which calculates packets (see also Appendix A) and particle trajectories (CAIPAT), and one which accepts data from CAIPAT and produces plot data in a DISSPLA compressed format ${ }^{2}$ (PATPLT). The compressed plot data files way be plotted on a calcoxp plotter or on a TExTROsIX graphics terminal using program QWTPOP. ${ }^{3}$ TORCAPP is intended to be especially useful in calculating injection paths in a separated sector cyclotron. Injection usur11y occurs in a valloy with low wagnetic field and thus the path is zelatively straight and in the radial direction. Looping wotion not about the origin may also be followed in TORCAPP. The Goc (Ceneral Orbit code)" employs an angle-dependent integration which is not satisfactory for this type of motion. TORCAPP, with time as the independent variable, can follow any general near-median-plane motion.

TORCAPP is structured to allow straightforward modification of the subroutines which determine the electric and magnetic f felds, and thus may be readily adapted to specialized uses such as central regiois studies, or acceleration calculations with unusual dee geometries. 


\section{CAPABILITIES AND FUNCTIONS}

\section{Calculations Performed in CALPAT}

CALPAT calculates the paths of one or more partigles from an initial time to a final time.

CALPAT allows any particle (as specified by its initial conditions: position, velocity, charge and wass) to be followed through time in a magnetic field. The code has provisions for using an isochronized field; i.e., a field may be input along with isochronizing factors (calculated by $(0)$ ) for that particular field and particle.

The user my initially specify the approximate distance the particle covers in one integration step. Internally, this quantity is converted to the time it takes to cover that distance for the initial velocity. The user may also specify at which times (i.e., at which integration steps) the particle position and velocity should be printed or written to disk for later plotting.

Initial position and velocity of the particle or particles may be specified in several ways. Initial conditions may be input in $x, y$ and $z$ coordinates or by specifying an initial radius, angle, and direction. Initial conditions for a packet of particles may be calculated from the given initial conditions of the central particle. Optionally, coordinates for up to nine particles may be input directly instead of being calculated.

The present version of CALPAT determines the magnetic field along the path, given field values in a median plane polar mesh. Subroutines BRECT, etc., described below, return the field components based on this situation. Any arbitrary magnetic field configuration may be allowed by modifying these routines.

\section{Printed Output from CALPAT and PATPLT}

Depending on input parameters, the following types of printout may be obtained.

1) A columnar listing, one particle at a time, of time, position, velocity, field value, radius, and angle at each time step requested.

2) A listing showing the position and velocity of all particle; at oic time, then another time, etc. 
3) A listing of the transverse displacenents and wonta, with respect to particle 1 , will be generated when packet plots are requested. The time of each packet is printed, along with the pooftion and velocity of particle 1 .

\section{Plots Generated fron PArLT}

Plotting in PATPLT is accomplished by using a vexy versatile plotting package called DISSPLA. ${ }^{2}$ This package is installed on the various conputer systens in Vak Ridge, ani is generally avallable at other DOE laboratories, and many univirsity certers. It can be accessed by linking in the appropriate libraries as shown in the sample JCL. PATPL produces a coapressed plot data file which way be plotted on the CALCOPP plotter or routed to the user's PDP-10 disk area and plotted on a TEKTROAIX graphics terminal.

Depending on input parameters, the following types of plots may be generated.

1) Individual particle trajectories, either one per plot, or all particles on one plot.

2) Particle trajectories by time ranges, f.e., all particles at one time range on one plot, or each particle at each time range on a separate plot.

3) Plots of transverse displacement and transverse womenta relative to particle 1 (packet plots) -- either R-packets or 2-packets with either one per page or four per page. 
3. General equTions miplemented

Equations of Motion in an Electronagnetic Field (defined in subroutine EQUA)

The equations of motion consist of the derivatives of position and velocity, each one broken down into its $x, y$, and $z$ components. The Lorentz relation is used.

$$
\vec{F}=\vec{m}=q(\vec{E}+\vec{V} \times \vec{B})
$$

where $=$ total force

$$
\begin{aligned}
& \vec{a}=\text { ass } \\
& \overrightarrow{\mathbf{a}}=\text { acceleration } \\
& \mathbf{q}=\text { charge } \\
& \vec{t}=\text { electrical field } \\
& \overrightarrow{\mathbf{v}}=\text { velocity } \\
& \vec{B}=\text { magnetic field. }
\end{aligned}
$$

Thus, the six equations of motion, derivatives with respect to time, are:

$$
\begin{aligned}
& \frac{d x}{d t}=v_{x} \\
& \frac{d y}{d t}=v_{y} \\
& \frac{d z}{d t}=v_{z}
\end{aligned}
$$

and, since $\vec{a}=\frac{d \vec{V}}{d t}$, then

$$
\begin{aligned}
& \frac{d V_{x}}{d t}=\frac{q}{m}\left(E_{x}+V_{y} B_{z}-V_{z}^{B_{y}}\right) \\
& \frac{d V_{y}}{d t}=\frac{q}{m}\left(E_{y}+V_{z} B_{x}-V_{x}^{B_{z}}\right) \\
& \frac{d V_{z}}{d t}=\frac{q}{m}\left(E_{z}+V_{x}^{B}-V_{y}^{B}\right) .
\end{aligned}
$$


Determinat ion of $x, y$, and $z$ Components of the Magnet ic Field

(Defined in subroutine BREC:)

Using a first-order Taylor expansion out of the median plane (1.e., $2=0 j$, the fjeld crmponeuts cas be writsen as

$$
\begin{aligned}
& B_{x}(x, y, z)=B_{x}(x, y, 0)+z \frac{\partial}{\partial z} B_{x}(x, y, C) \\
& B_{y}(x, y, z)=B_{y}(\ldots, y, 0)+z \frac{\partial}{\partial z} B_{y}(x, y, C) \\
& B_{z}(x, y, z)=B_{z}(x, y, 0)+z \frac{\partial}{\partial z} B_{z}(x, y, 0)
\end{aligned}
$$

We ascume, from nedian plane symmetry,

$$
\begin{aligned}
& B_{x}(x, y, 0)=0 \\
& B_{y}(x, y, 0)=0 \\
& \frac{\partial}{\partial z} B_{z}(x, y, 0)=0 .
\end{aligned}
$$

Titis leaves as unkn wns:

$$
\begin{aligned}
& B_{. \rightarrow}(x, y, 0) \quad \text { (Field datz, input to calculation) } \\
& \frac{\partial B_{z}}{\partial z}(x, ; 0) \\
& \frac{\partial B_{y}}{\partial z}(x, y, 0)
\end{aligned}
$$

Interpolation to get Field Value at the Desired Point $B_{2}(x, y, 0)$

(Defined in subroutine BINTRP)

The $x$ and $y$ values of the desired point are converted to a radius and angle sinc: the median plans magnetic fleld values are input as an $(r, A)$ mesh. A three-point statment function TRELAG is used twice to perform the two-variable lagrangian inte:polation.

Two-Point Central Differencing used in Calculating Partiai Derivatives of the Magnetic Field (defined in subroutine BPRDME)

Using the fact that the curl $\vec{B}=0$, we know that

$$
\frac{\partial B}{\partial z}=\frac{\partial B}{\partial x}
$$




$$
\frac{\partial B_{y}}{\partial z}=\frac{\partial B_{z}}{\partial y} \text {. }
$$

Then to find the field derivatives at the central point with respect to $x$ and $y$, four points are selected relative to the central point, one each in the positive and negative $x$-direction and the positive and regative $y$-direction. The foll' wing equations are used:

$$
\begin{aligned}
& \frac{\partial B_{z}}{\partial x}=\left(B_{2}-B_{4}\right) /(2 . * x H) \\
& \frac{\partial B_{z}}{\partial y}=\left(B_{3}-B_{5}\right) /(2 . * Y H)
\end{aligned}
$$

wich

$$
\begin{aligned}
& B_{2}, B_{4}=f \text { ield values of poirits in positive and negative } \\
& x \text {-direction } \\
& B_{3}, B_{5}=\text { ficid values of points in positive and negative } \\
& y \text {-direction } \\
& \mathrm{XH}=\mathrm{x} \text {-distance from central point to } \mathrm{B}_{2}, \mathrm{~B}_{4} \\
& \mathrm{YH}=\mathrm{y} \text {-distance from cencral point to } B_{?} \text {. } 5 \text {. }
\end{aligned}
$$

\section{Calculation of Transverse Distances and Momenta ror Packet Plots}

(Def ined in subroutine P:TPAK)

R-packets and Z-packets are treated separately, with the R-packet ignoring all Z-motion. Appendix A defines a packet.

For R-packets, transverse distances and momenta are calculated relative to a line perpendicular tc the momentum of particle 1 (trangverse momentum line). To obtain the position and momentum of particle $\mathrm{j}$ at its intersection with the transverse momentus line, the apjroximation is made that the particle is traveling in a circular patin. (See Fig. A.2 in Appendix A.) The intersection of the circular path and the eransverse momentum line is obtaired. The distance (displacem -nt) between the point of incersection and the point $\left(x_{1}, y_{1}\right)$ is calculated. The sign of the displacement is conventionally chosen to be positive for positions to the right of particle one in the median plane, as viewed along the path of particle one. 
To $f$ ind the transverse momentum displacement, une deteranines the new components of $P$ af ter the momentum vector has beet moved along the circle to the point of intersection. Then,

$$
\begin{aligned}
& P_{x_{j}}=P \cos \Phi_{2} \text { and } \\
& P_{y_{j}}=P \sin \Phi_{2}, \text { where } \\
& \Phi_{2}=\Phi_{1}+\Phi, \text { with }
\end{aligned}
$$

$\Phi_{1}$ being the original momentum angle, and $\$ 1$, the angle of rotation along the circular path. The transverse momentum is found by differencing

$$
\theta_{j}=\tan ^{-1}\left(P_{y_{j}} / P_{x_{j}}\right)
$$

and

$$
\theta_{1}=\tan ^{-1}\left(P_{y_{1}} / P_{x_{1}}\right)
$$

For $z$-packets the transverse distance is just $z_{j}$. The transverse momentum is $\tan ^{-1}\left(P_{z_{j}} / P\right)$.

For both type packets, transverse momentum is scalted to milliradians and transverse displacement is scaled to m 111 imeters.

[Note: The FORTRAN function ATAN2 was used in finding $\tan ^{-1}$.]

\section{Runge-Kutta Integration}

The equations of motion described earlter are integrated over time with subroutine DE. ${ }^{5}$ This Runge-Kutta routine usp a selfadjusting step size. The accuracy parameters RELERR and ABSERR should be adjusted for satisfactory numerical behavior for any partfcular problem. 


\section{DESCRIPTIGN OF SUEKOUTINES}

\section{CALPAT}

1) MAIN

Initializes variables

Reads option type variables

Calls INPUTF

Calls INPUTP

Calls PARTCL

2) INPUTF

Reads in field characteristics and data

Multiplies field by isochronizing factors

Converts field to negative tesla

3) INPUTP

Reads in particle defining information

Reads beginning, ending times and integration step size

Converts all variables to MKi units

Calls PACKET

4) PACKET

Converts $R$, NTI and $T I$ into position and velocity in $x, y$, and $z$ coordinaizs.

Calculates a nine-particle elliptica: packet in $r$ or $z$ and roturns position and velocity to calling routine.

Calls FPHI.

5) FPHI

Finds angle that subtends equal segments of an arc on an ellipse.

Calls function SOYANK ${ }^{6}$ to integrate function F.L.2.

6) PARTCL

Loops over NP (number of particles) times.

Decides at which time steps position and velocity information should be saved.

Calls $D F^{5}$ to integrate equations of motion.

Writes position, momentum, and time out to scratch disk.

Prints time, position, velocity, field value if PRTOPT >0. 
7) DEE

Calls EQUA to define equations to be integrated.

Integrates equations orer time.

8) EQUA

Defines equations to be integrated.

Calls BRECT to find field components in $x, y$, and $z$ directions.

9) BRECT

Sets up points around central point that will be needed in calculating field derivative.

Calls BINTRP to, interpolate to find field value at central point and those around it.

Calls BPRIME to calculate partial field derivatives.

Defines equations determining field components in $x-, y-$ and $z-$ directions.

10) BINTRP

Loops over number of points to be interpolated.

Finds $R$ and $\theta$ of field position to be interpolated.

Determinas subset of field arraj needed for interpolation.

Calls statement function TRELAG to perform two-variable lagrangian interpolation.

11) BPRIME

Defines equations that calculate partial field derivatives using 3-pt Lagrangian differencing.

\section{PATPLT}

1) MuiN

Read in position, velocity, and time data that was calculated and saved by CALPAT.

Depending on type of plotting specified, one of the following three calls is made:

CALL PLOTIP

CALL PLTPAK

CALL PLOTNP 
If priopt $<0,3$ table is printed stowing position and velocity of all particles at one time, then another time, etc.

2) PLOTNP*

This subroutine is called when mor than one particle trajectory is calculated and a packet plot is not desired. A variety of plot combinations may be achieved depending on the number of time ranges and number of particles per plot.

Call COMPRS to cause plot data to be stored in a compressed file. Determine number of plots to be gencrated.

Loop over number if plots.

CALL BGNPL

Determine $x, y$, and $z$ minimum and maximum values

Cal1 TITLE or TITL3D

Call GRAF or GRAF3D

Call CURVF. or CURV3D

Cal1 ENDPL

Ca1I DONEPL.

3) PLOTIF

This subroutine is called when only one particle crajectory is calculated.

Call COMPRS.

Determine number of flots to be generated, depending on number of time ranges specified.

Loop over number of plots.

Determines $x, y$, and $z$ minimum and maximun values.

Cal1 BGNPL

Ca11 TITLE or TITL3D

Call GRAF Or GRAF3D

Call CURVE or CURV3D

Label plot with particle number, time, mass, charge, and energy

Cal1 ENDPL.

Cal1 DONEPL.

The fundamental modules in the plotting program are in DISSPLA. 


\section{4) PLTPAR}

This subroutine is calied wher a packet plot is desired.

Loop over time steps

Plck o.1t position and monentum for this plot out of large dat: array.

Calculate transverse displacentent and transverse monentum.

Call corprs

Deternine number of plots to generate

Set up orizins for plots

Loop over number of plots

Call BGLPL

Call PHYSOR

Call TITLE

Call CROSS

Call RLINT to put particle norjers on their packet locations

Label plot

Call ENDPL

Call DONEPL. 
5. DATA INPUT GLIDE

CALPAT - Unit 5

1. Plotting variables Format (6I5)

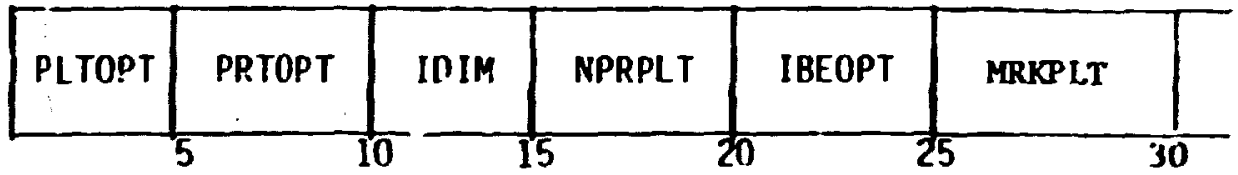

2. Calculation type variables Fcrnat (3I5)

\begin{tabular}{|l|l|r|r|}
\hline IPAK & IOPT & IPRNTB \\
\hline 5
\end{tabular}

3. Field size variables Format (415)

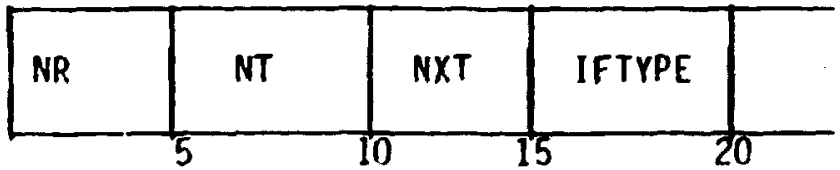

4. Field step sizes and accuracy parameters format (4F10.0)

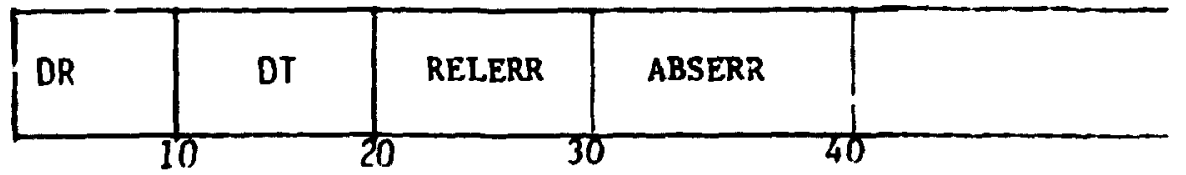

5. Field format Format (18A4)

Note: This character string would be something like '(9F8.1)'.

\begin{tabular}{|l|c|c|c|cc}
\hline FMT (1) & FMT (2) & FMT(3) & FMT (4) & $\cdots$ & FMT (18) \\
\hline
\end{tabular}


6. Isochronizing factors

Format

(8F10.0)

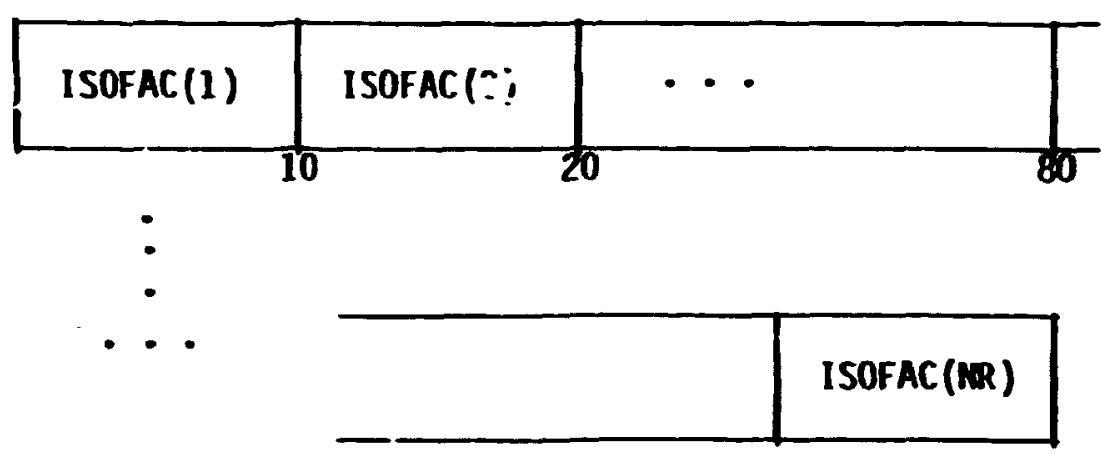

7. Packet widths and phase space areas Format (4E10.5) Note: This group is read only if IPAK $\neq 0$.

\begin{tabular}{|l|l|l|l|l|}
\hline PWIDTH (1) & PSPACE (1) & PUIDTH (2) & PSPACE (2) \\
\hline 10 & 20 & 30
\end{tabular}

8. Particle and integration variables format (6E10.5)

\begin{tabular}{|c|c|c|c|c|c|}
\hline E & FMASS & $Q$ & STPSIZ & TINT & TMAX \\
\hline
\end{tabular}

9. Time - plotting variables

Format $(E 15.6,15, E 15.6)$ Note: This group read only if IBEOPT $\neq 0$. This group must consist of 101 ines, even if there are not 10 ranges specified.

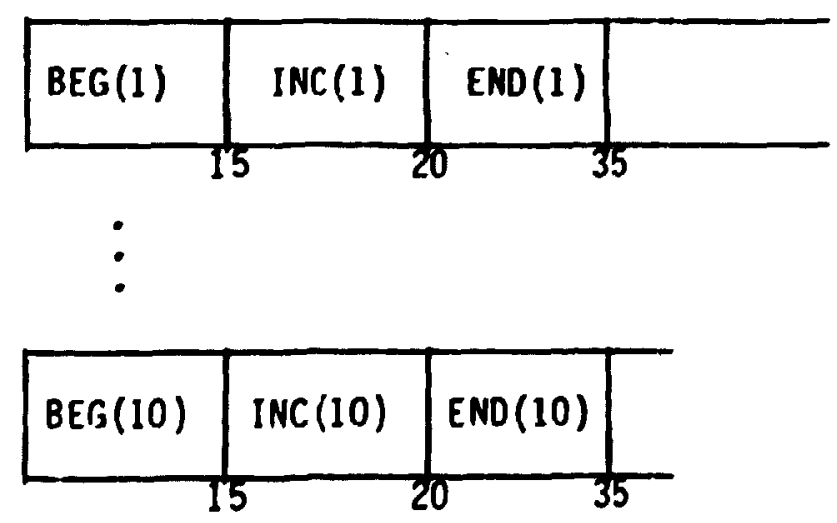


10. Number of particles and interpolation mesh-size adjustor Format (I5,F10.0)

\begin{tabular}{|l|l|l|}
\hline NP & FJDGE & \\
\hline 5
\end{tabular}

11. Particle position variables Format (F10.2, I5, F10.2, 2E15.6) Note: This group read only if IOPT $\neq 1$. If IPAK $\neq 0$, this group is read for particle 1 only. If IPAK $=0$, this group is read for NP particles.

\begin{tabular}{|c|c|c|c|c|}
\hline$R(1)$ & MII (1) & $T I(1)$ & $s(3,1)$ & $v(3,1)$ \\
\hline
\end{tabular}

\begin{tabular}{|l|l|l|l|l|}
\hline$\left.R^{\prime} N P\right)$ & $N T I(N P)$ & $T I(N P)$ & $S(3 N P)$ & $V(3, N F)$ \\
\hline 10 & & & & \\
\hline
\end{tabular}

12. Particle position variables Format (3E 15.6/3E15.6)

Note: This group read only if IOPT $=1$. If IPAK $\neq 0$, this group is read for particle 1 only. If IPAK $=0$, this group is read for NP particles.

\begin{tabular}{|l|l|l|l|}
\hline$s(2,1)|s(3,1)| \ldots$. \\
\hline
\end{tabular}
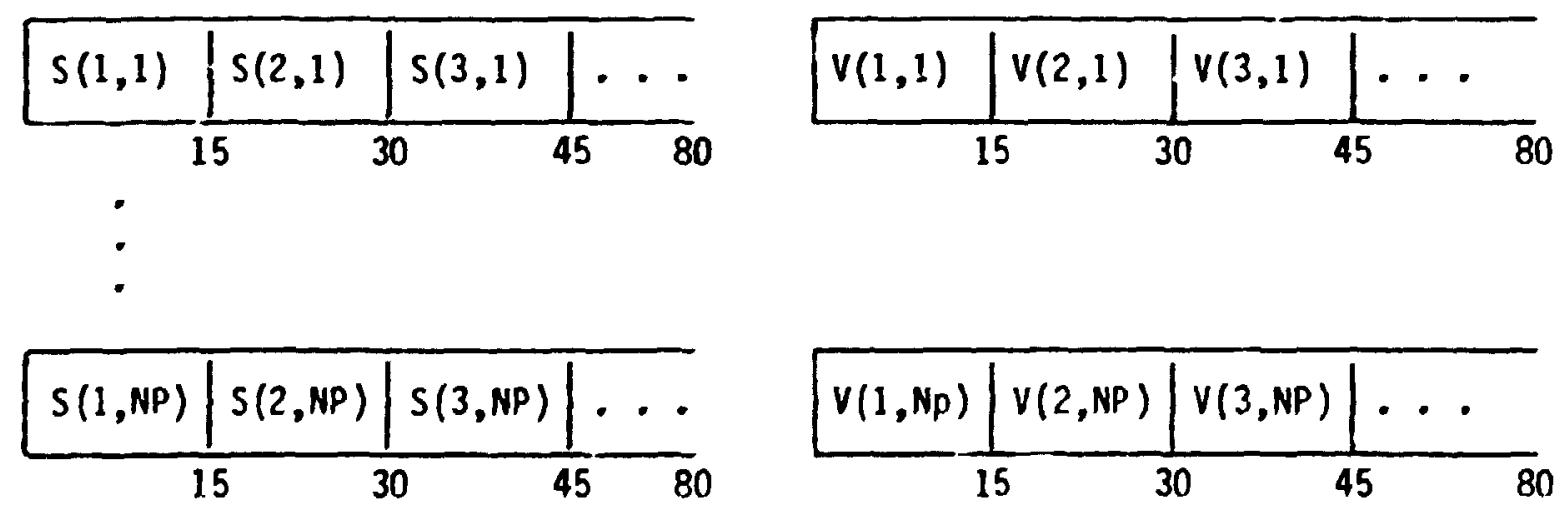


\section{CALPAT - Unit 10}

1. Field data

Format $[72 \times /(F M T)]$

Note: This format is valid only if IFTYPE $=0$. If IFTYPE $=1$,

there are no blank cards before each radius and field is read with format FMT only.
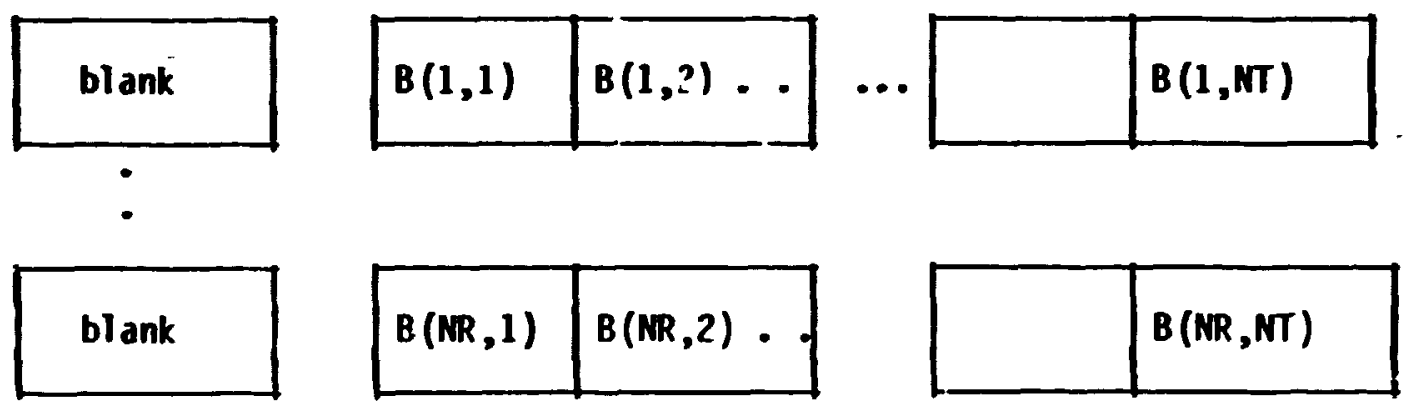


\section{PATPLT - Unit 11}

Note: Input to PATPLT is normally read in from disk after being written by CALPAT and the user need not alter the input. However, if the user wishes to use the same particle position and velocity data more than once. plotting the data in various ways, he may do so by substituting his input for input to unit 11 .

1. Plotting variables Format $(815,3 F 5.0)$

\begin{tabular}{|l|c|c|c|c|c|}
\hline PLTOPT & PRTOPT & NP & IDIM & NPEPLT & MRKPLT \\
\hline
\end{tabular}

\begin{tabular}{|l|l|l|l|l|}
\hline IBDIM & IPAK & ESAV & FMSAV & QSAV \\
\hline
\end{tabular}

Note: IBDIM, ESAV, FMSAV, and QSAV should not be altered; therefore they do not appear in the input definitiors.

2. Plotting variables Format $(1515)$

Note: ITSTOP and ITIMPP should not be altered since they deal with the way the position and velocity data was written and the data must be read just as ft was written.
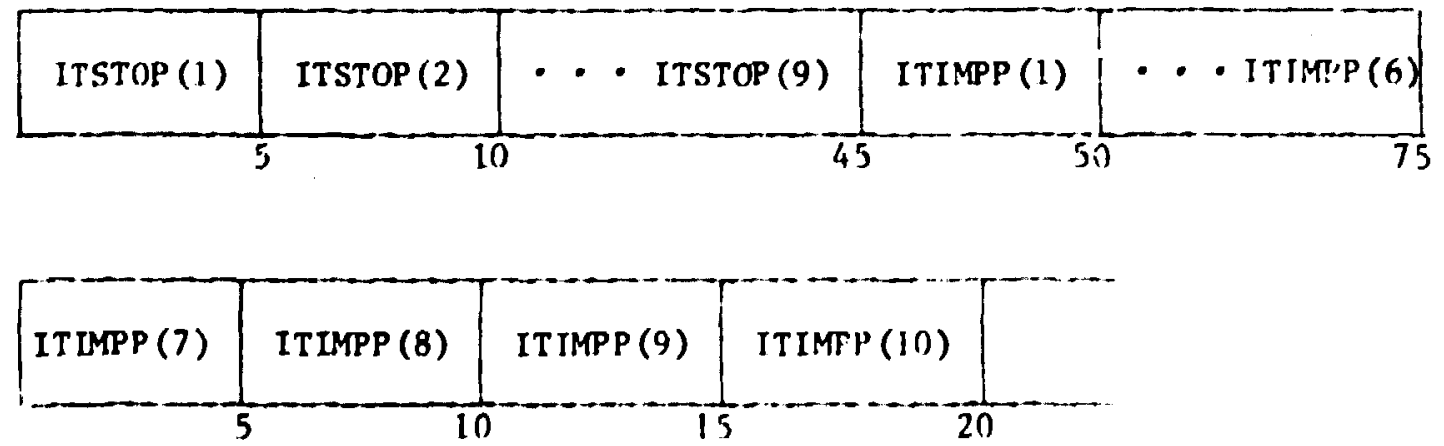
Input Variable Definitions

Abbreviations Used:

Subroutine Names

$$
\begin{array}{lll}
\text { IF } & - & \text { INPUTF } \\
\text { IP } & - & \text { INPUIP } \\
M & - & \text { MAIN FOT CAL'AT }
\end{array}
$$

Data Units:

$$
\begin{aligned}
& \text { AYU - } \quad \text { atomic mass units } \\
& \text { C } \quad \text { control variable } \\
& \text { CI - centimeter } \\
& \text { DEG - degrees } \\
& \text { EU - Electron units } \\
& \text { G - gauss } \\
& \text { MEV - million electron volts } \\
& \text { MA - millimeter } \\
& \text { MRAD - milliradian } \\
& \text { S - second }
\end{aligned}
$$




\begin{tabular}{|c|c|c|c|c|}
\hline 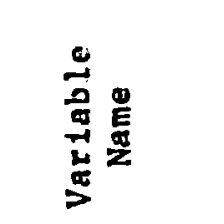 & 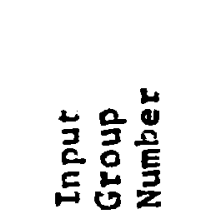 & 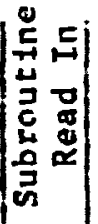 & 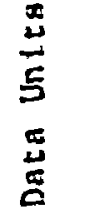 & Definftions \\
\hline ABSERR & 4 & IF & C & $\begin{array}{l}\text { Accuracy parameter for subroutine } \\
D E^{5} \text {. Absolute error test- }\end{array}$ \\
\hline$B(100,150)$ & 1/Unit : 0 & IF & G & $\begin{array}{l}\text { B-field array. First index is azimuthal, } \\
\text { second index is radial. If a } \\
\text { partial field is input, i.e., only one } \\
\text { sector, the program assumes the field } \\
\text { is symetric. }\end{array}$ \\
\hline BEG (10) & 9 & $\mathbf{I P}$ & $\mathbf{s}$ & $\begin{array}{l}\text { Array of beginning times at which piots } \\
\text { are produced. Used with END and INC } \\
\text { arrays. Maximum of } 10 \text { time ranges } \\
\text { may be requested. }\end{array}$ \\
\hline DR & 4 & IF & $\mathbf{I N}$ & Radial srep size of to field array. \\
\hline DT & 4 & IF & DFr: & Azimuthal step size oí B-field array. \\
\hline$E$ & 8 & IP & MEV & $\begin{array}{l}\text { Energy of particle or particles to be } \\
\text { tracked. }\end{array}$ \\
\hline END & 9 & It & $\mathbf{S}$ & $\begin{array}{l}\text { Array of ending times at which piots } \\
\text { are prurluced. BEG(I), FND(I), and } \\
\text { INC(I) form a time range at which plots } \\
\text { are desired. }\end{array}$ \\
\hline FMASS & 8 & IP & AMU & Mass of particle to be tracked. \\
\hline FMT & 5 & If & C & $\begin{array}{l}\text { Format in which field array is read in. } \\
\text { This is a literal string, such as } \\
\text { '(9F8.1)'. }\end{array}$ \\
\hline FUDGE & 10 & IP & $c^{-}$ & 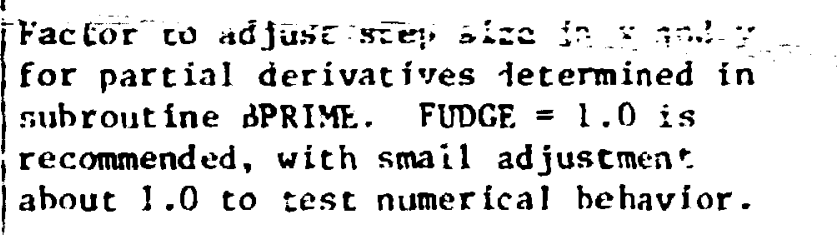 \\
\hline IBEOPT & 1 & M & $c$ & $\begin{array}{l}=0 \text { implies BEC, FND, INC arrays will } \\
\text { not be read in, i.r., plots are } \\
\text { produced from TINT to TMX. } \\
=1 \text { implies time ranges (BFG, FND, } \\
\text { INC) will be read in. }\end{array}$ \\
\hline IDIM & 1 & M & $c$ & $\begin{array}{l}=2 \text { implies two-dimenstomal plot } \\
\text { qenerated. } \\
=3 \text { implites three-dimensional plot } \\
\text { generated. }\end{array}$ \\
\hline
\end{tabular}




\begin{tabular}{|c|c|c|c|c|}
\hline 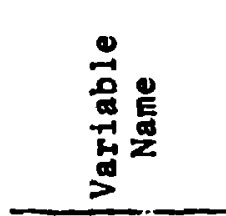 & 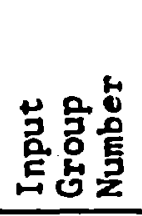 & 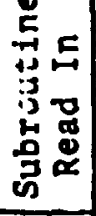 & 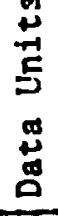 & Pefinitions \\
\hline II:TYPE & 3 & IF & C & $\begin{array}{l}=0 \text { implies field to he read is from } \\
\text { ORIC measured data, i.e., a blank } \\
\text { card before each radius, with the } \\
\text { initial azimuth of the field } \\
\text { measured at } 63^{\circ} \text {. } \\
=1 \text { impiies no blank card will be } \\
\text { read before each radius and the } \\
\text { first azimuth is taken to be at } 0^{\circ} .\end{array}$ \\
\hline INC $(10)$ & 9 & IP & C & $\begin{array}{l}\text { An array used with BEG and END--used } \\
\text { to indicate how often time steps in } \\
\text { a certain range will be printed or } \\
\text { plotted. Ex.: If INC(I) = 5, every } \\
\text { fifth time step from time BEG(I) to } \\
\text { time END(I) will be saved fo: printing } \\
\text { or plotting. }\end{array}$ \\
\hline IOPT & 2 & M & C & $\begin{array}{l}=0 \text { implies particle coordinates are } \\
\text { input as initial radius (K), ini- } \\
\text { tial angle (NTI), and direction } \\
\text { (TI). } \\
=1 \text { implies initial particle position } \\
\text { is defined by } x, y \text {, and } z \text { co- } \\
\text { ordinates. }\end{array}$ \\
\hline IPAK & 2 & M & C & $\begin{array}{l}=0 \text { implies no packet to be calculated, } \\
\text { i.e. coordinates are input for } \\
\text { NP particles. } \\
=1 \text { implies } R \text { packet will be calculated. } \\
=2 \text { implies } Z \text { packet will be calculated. } \\
=3 \text { implies both } R \text { and } Z \text { packets will } \\
\text { be calculated. }\end{array}$ \\
\hline IPRNTB & 2 & M & c & $\begin{array}{l}=0 \text { implies field data and isochronizing } \\
\text { factors will nut be printed. } \\
=1 \text { implies field data and isochronizing } \\
\text { factors will be printed. }\end{array}$ \\
\hline ISOFAC (NR) & 6 & IF & C & $\begin{array}{l}\text { An array of factors, one for each } \\
\text { radius, by which data is mul tiplied } \\
\text { to adjust the field to an isochronous } \\
\text { or other destred radial vartation. }\end{array}$ \\
\hline
\end{tabular}




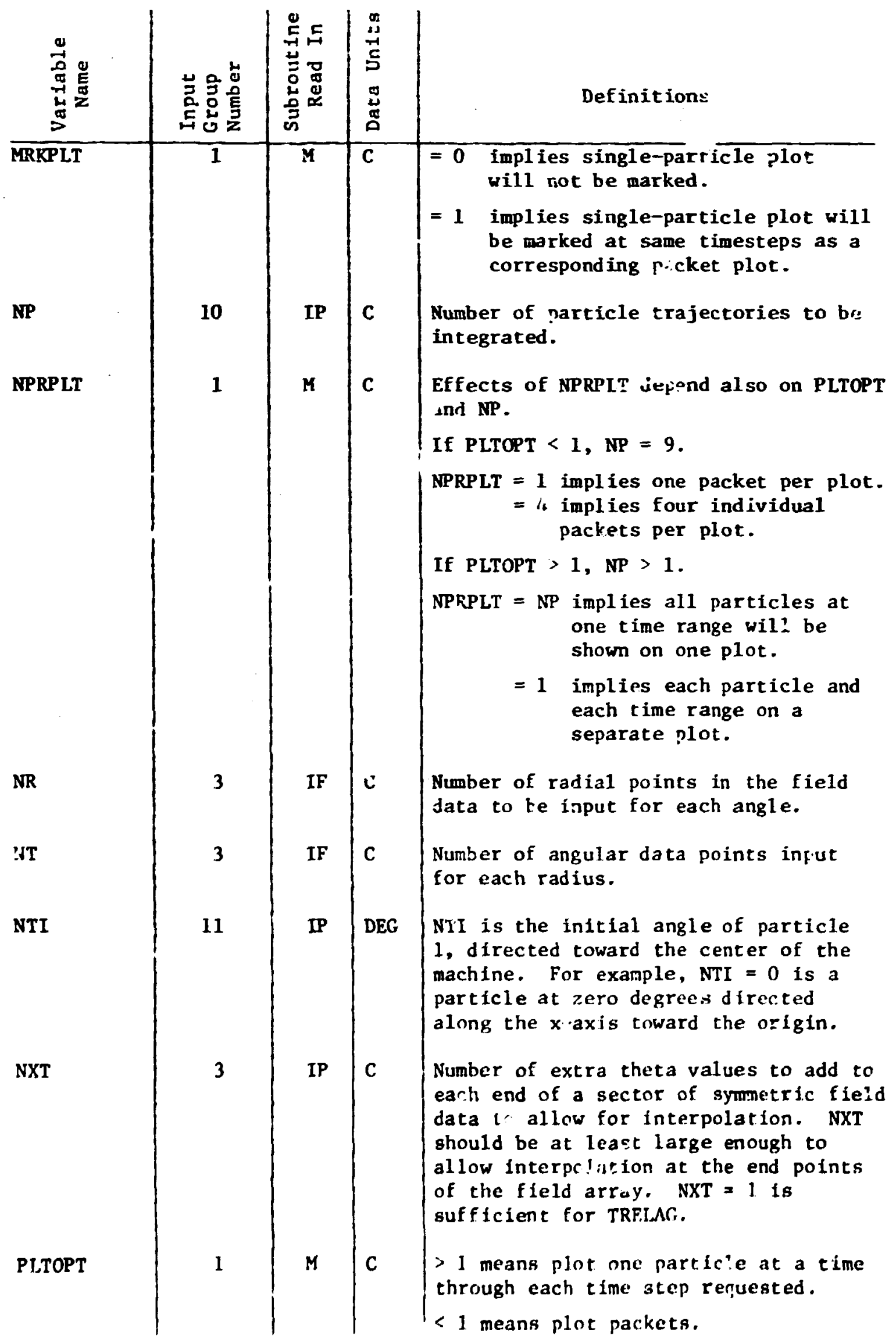




\begin{tabular}{|c|c|c|c|c|}
\hline 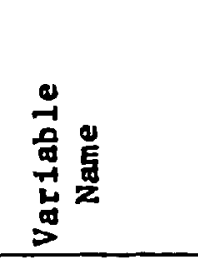 & 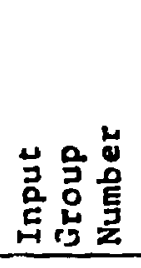 & 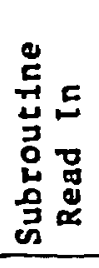 & 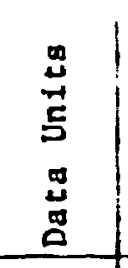 & Descriptions \\
\hline PRTOPT & 1 & M & C & $\begin{array}{l}>1 \text { means printout will consist of all } \\
\text { time steps requested for one particle, } \\
\text { then another particle, etc. } \\
\text { < } 1 \text { means printout will consist of } \\
\text { position and velocity of all particles } \\
\text { at one time step, then another time } \\
\text { step, etc. }\end{array}$ \\
\hline PSPACE (2) & 7 & IP & $\begin{array}{l}\text { MM- } \\
\text { MRPD }\end{array}$ & $\begin{array}{l}\text { Phase space area of packet to be calcu- } \\
\text { lated. PSPACE(1) is for R-packet, } \\
\text { PSPACE(2) is for Z-packet. }\end{array}$ \\
\hline PHIDTH (2) & 7 & IP & MM & $\begin{array}{l}\text { Packet width. PWIDTH(1) is for R- } \\
\text { packet, PWIDTH(2) is for Z-packet. }\end{array}$ \\
\hline $\mathbf{Q}$ & 8 & IP & EU & Charge of particle in electron units. \\
\hline $\mathbf{R}$ & 11 & IP & CM & Radius of particle at initial position. \\
\hline RELERR & 4 & IF & C & $\begin{array}{l}\text { Accuracy parameter for subroutine } \mathrm{DE}^{5} \text {. } \\
\text { Relative error test. }\end{array}$ \\
\hline$s(3,9)$ & 12 & IP & $\mathbf{C M}$ & $\begin{array}{l}\text { Particle position in } x, y, z \text { coordinates. } \\
\begin{aligned} \text { First subscript } & =1 \text { imp?ies } x \\
& =2 \text { implies } y \\
& =3 \text { implies } z\end{aligned} \\
\text { Second subscript is particle number. }\end{array}$ \\
\hline TI & 11 & IP & DEG & $\begin{array}{l}\text { Implies direction of packet. Positive } \\
\text { TI is measured counterclockwise from } \\
\text { radial NTI line. TI }=0 \text { assumes packet } \\
\text { is directed toward center along NTI } \\
\text { line. }\end{array}$ \\
\hline TINT & 8 & IP & SEC & $\begin{array}{l}\text { Initial time at which integration } \\
\text { begins. }\end{array}$ \\
\hline $\operatorname{TMAX}$ & 8 & IP & SEC & Final time at which integration ends. \\
\hline$v(3,9)$ & 12 & IP & $\begin{array}{l}\text { CM/ } \\
\text { SEC }\end{array}$ & $\begin{array}{l}\text { Particle velocity in } x, y \text {, and } z \\
\text { coordinates. Subscripts are used } \\
\text { the same as for } S \text {. }\end{array}$ \\
\hline
\end{tabular}




\section{PLOTTING PROCEDURE}

1. Once a compiessed piot daca set is generated ia PATPLT, a postprocessor izugrar. must be executed to plot the data. The data set may be postprocessed on a CALCOMP plotter or a TEKTRONIX graphics terminal. JCL to execute the CALCOHP postprocessor may be seen on page 2\%.

2. To postprucess on a TEKTRONIX terminal at ORNL, a compressed file must have been sent to the user's PDP-10 disk area. The JCL described for sending compressed data to the PDP-10 would cause a file to be sent to the disk area $[6137,67]$ and it would be named LB:Ll.PCH. The following sequence of commands would cause the file to be plotted. (The notation - $C R>$ means carriage return.)

RENAME FOR24.POP = LBMI.PCH 〈CR>

ASSIGN TTY LPT $: C R>$

R QWKPOP <CR >

(At this point the program asks for plotting commands. To plot all plots in the file, respond with $\langle C R\rangle\langle C R\rangle$.) Other postprocessor comands may be used to change the size of the plots, etc.

After one plot has been drawn and the user is ready to see the next plot, simpl, type a $\langle\mathrm{CR}>$ and plotting wall proceed. 
7. EXAMPLE JCL

SAMPLE .ICL IOR EXECUTING CALPAT

//LEMIN 1 JOE (1416弓), 'SAVEÖ157,67 XCSDA214'

1/ESGLO CPU1

//E CLASS CPUG $1=\angle 0 S, I C=1.5$

/" hüUTt PUACh REMO1t5

/EGGUTE RHINT LCCAL

$1 /{ }^{*}$

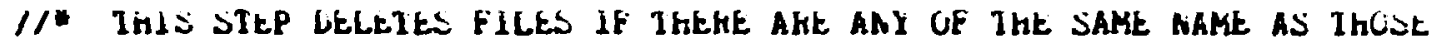

1/* Ti bE CKEATED

/1*

//STEPO EXEC SPDASCK

I/SISIN DD.

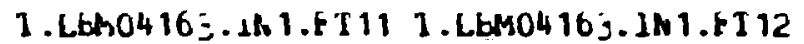

/t"

/ HUW EXEC FOKIGCLG, LIb=LAE,

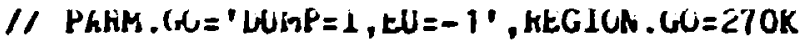

1/.

1/.

11* OBd CONTKINS INCCPY.F4[6]57,j0], LhLPAT.LE, ve,

1/. ANU FaCKET.F4

1/*

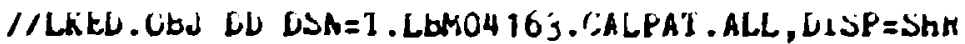

//LKED.SISIN UL

IMCLUDE UEJ

$1 *$

(continued on next page) 


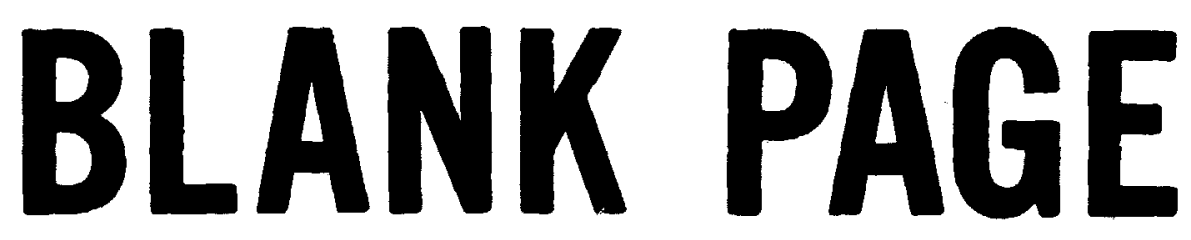




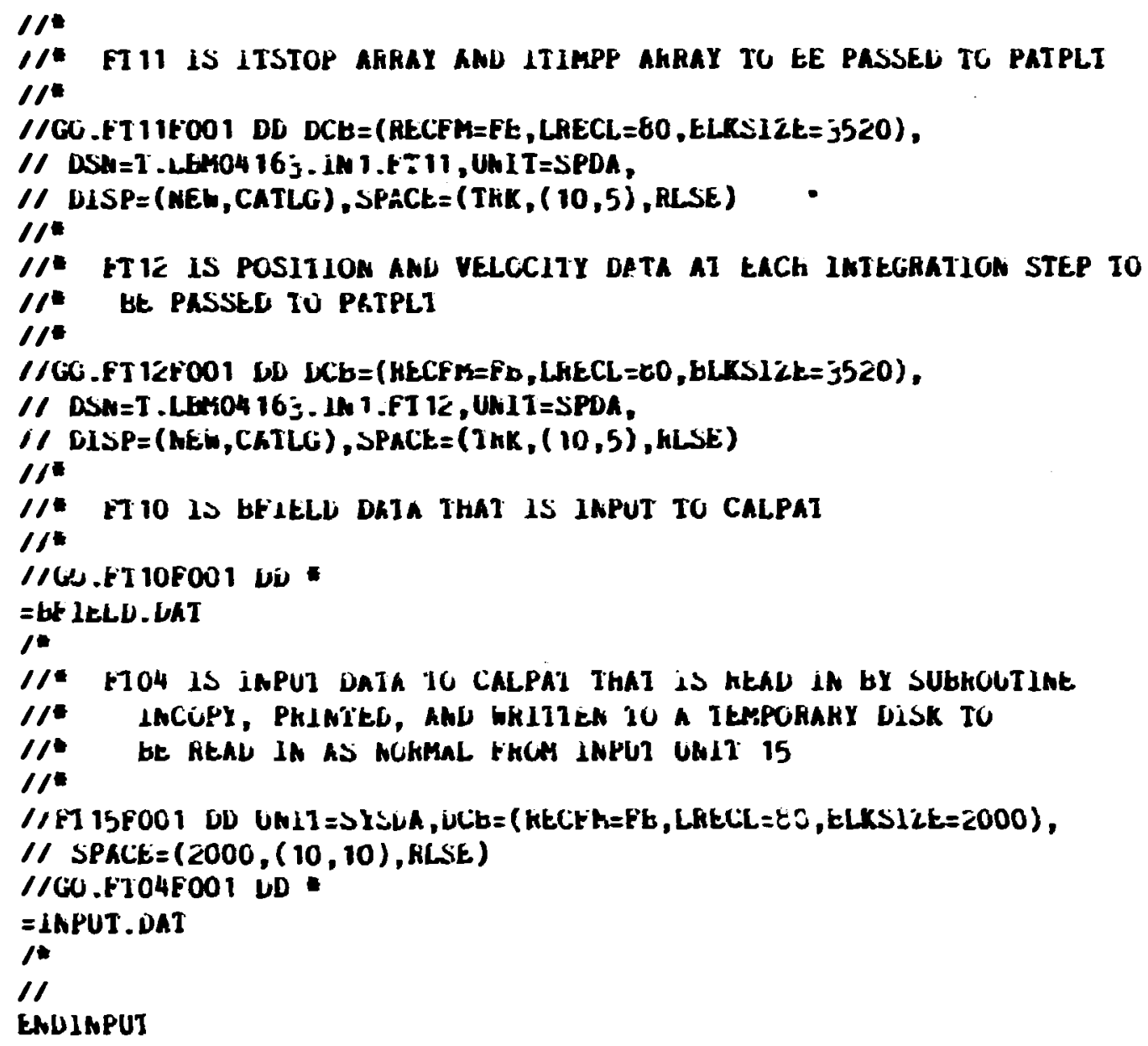


SAMPLE JCL TO EXECUTE CALCOMP POSTPROCESSOR

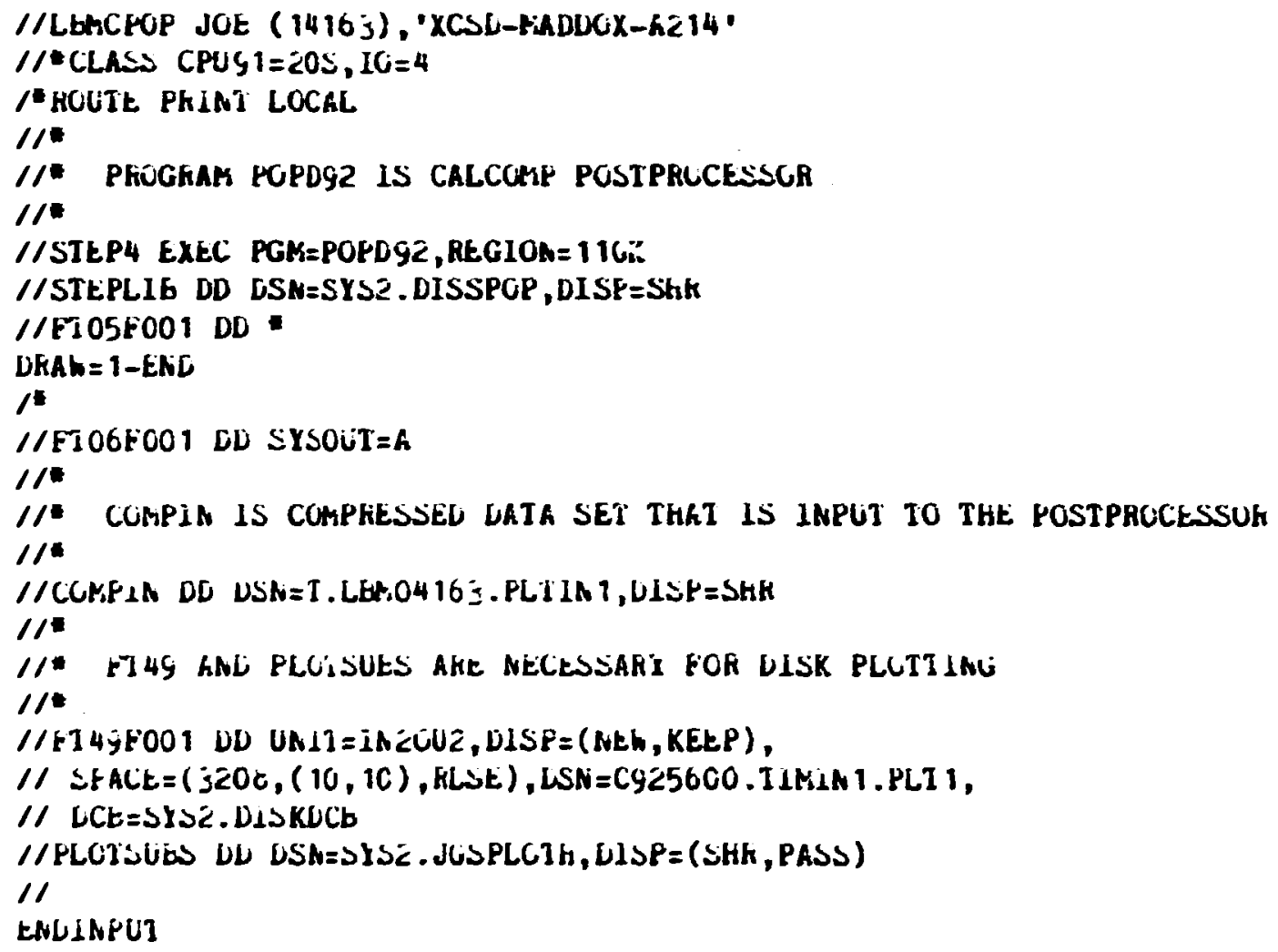


SAYPLE JCL TO JEND COMPRESSED DATA TO PDP-?O DISR AREA

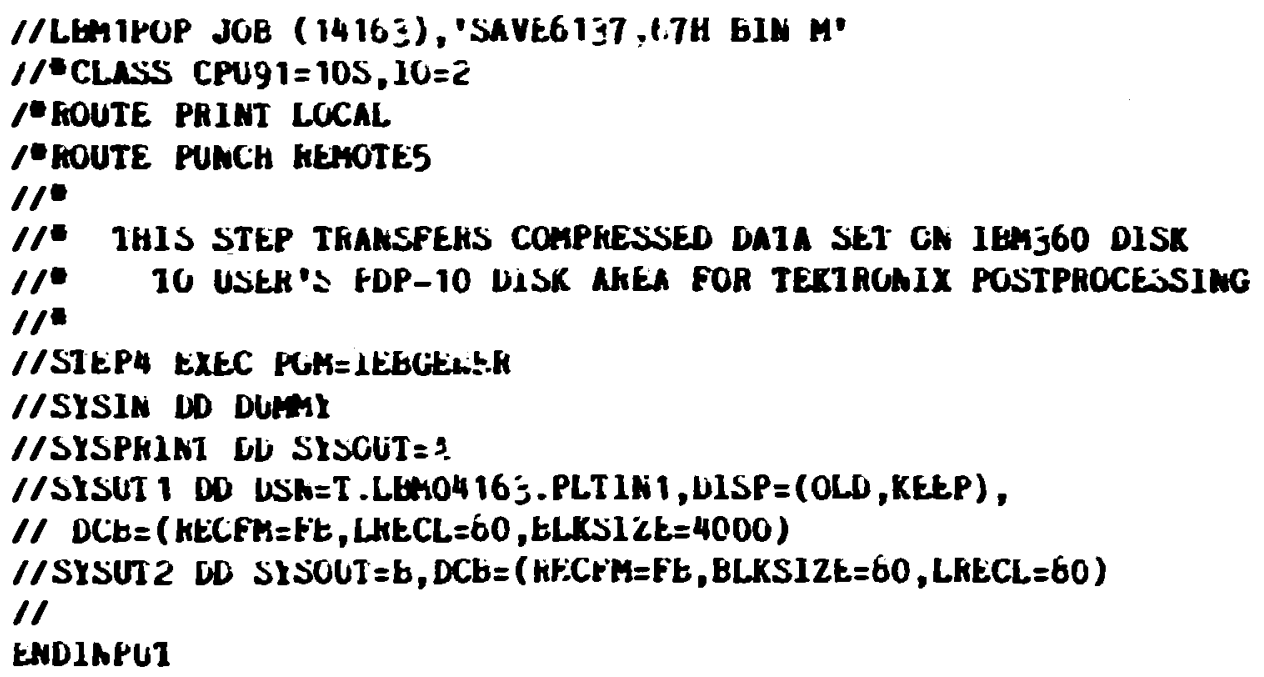




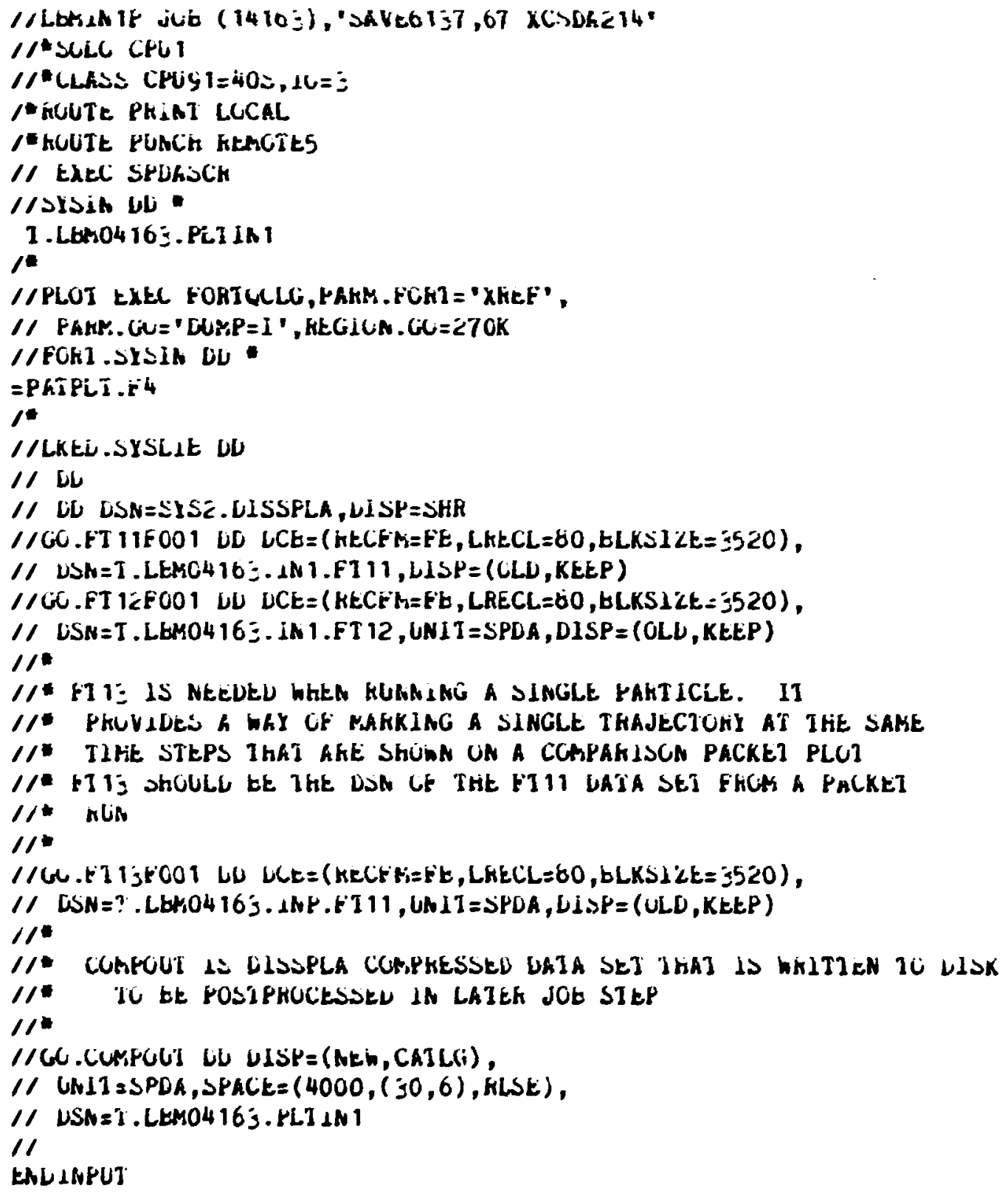




\section{EXAMPLE CALCLLLATIONS}

Example 1:

The input data set (Fig. 8.1) will calculate an injection trajectory for a particle in an ORIC magnetic field. The particle used is $75 \mathrm{MeV}{ }^{12} \mathrm{C}^{+2}$ with the path followed from time zero to $0.6 \times 10^{-7}$ seconds. The particle is initially positioned at $135^{\circ}$ at a radius of approximately $28 \mathrm{~cm}$. These initial conditions were those of an equilibrium orbit calculazed by $\operatorname{GOC}^{4}$. Figure 8.2 was produced by program PATPLT, with input from program CALPAT using the data set in Fig. 8.1. Note: To simulite an injection path from an equilibrium orbit in which the particle tracks backwards from the foil, the signs of $P_{x}$ and $P_{y}$ should be reversed and either the signs of tive isochronizing factors reversed or the charge made negative (implying a sign change for the field).

Example 2:

The input data set (Fig. 8.3) in CAlPAT will calculate the trajectories of a nine-particle packet. The central particle has the same initial conditions as the particle in Example 1. Initial fositions and velocities of the other eight particles are calcilated in the program.

Figure 8.4 shows the packet position it eight different times during the trajectory. The $x$ and $y$ coordinares of particle 1 are printed in order tol show the absolute position of the whole packet.

\section{Example 3:}

The fupu: data set (Fig - 8.5) In CALPAT calculates a trajectory of a particle Injected along the edge of $a$ hill and with a charge that would result from pre-inferition stripping. The magnetic fleld is that c: a $k=440$ separated sector machine with four-fold symetry. The particle used is $22.5 \mu_{:} v^{127} \mathrm{~T}^{+34}$. It is infertod at an angle of $28^{\circ}$.

stripping before injection would allow a form of precessional injection. This approach has been used in the past as a means to transporr beams from an external. Ion source to the cyibloron central reginn.6 Here the princlple is the aame, except the lons have an energy of $225 \mathrm{MeV}$. The trajectory shown in Fig. 8.6 fllustrates the general nature of the code, which allows integration of any arbitary (near medtain plane) moticn is a function of time. 


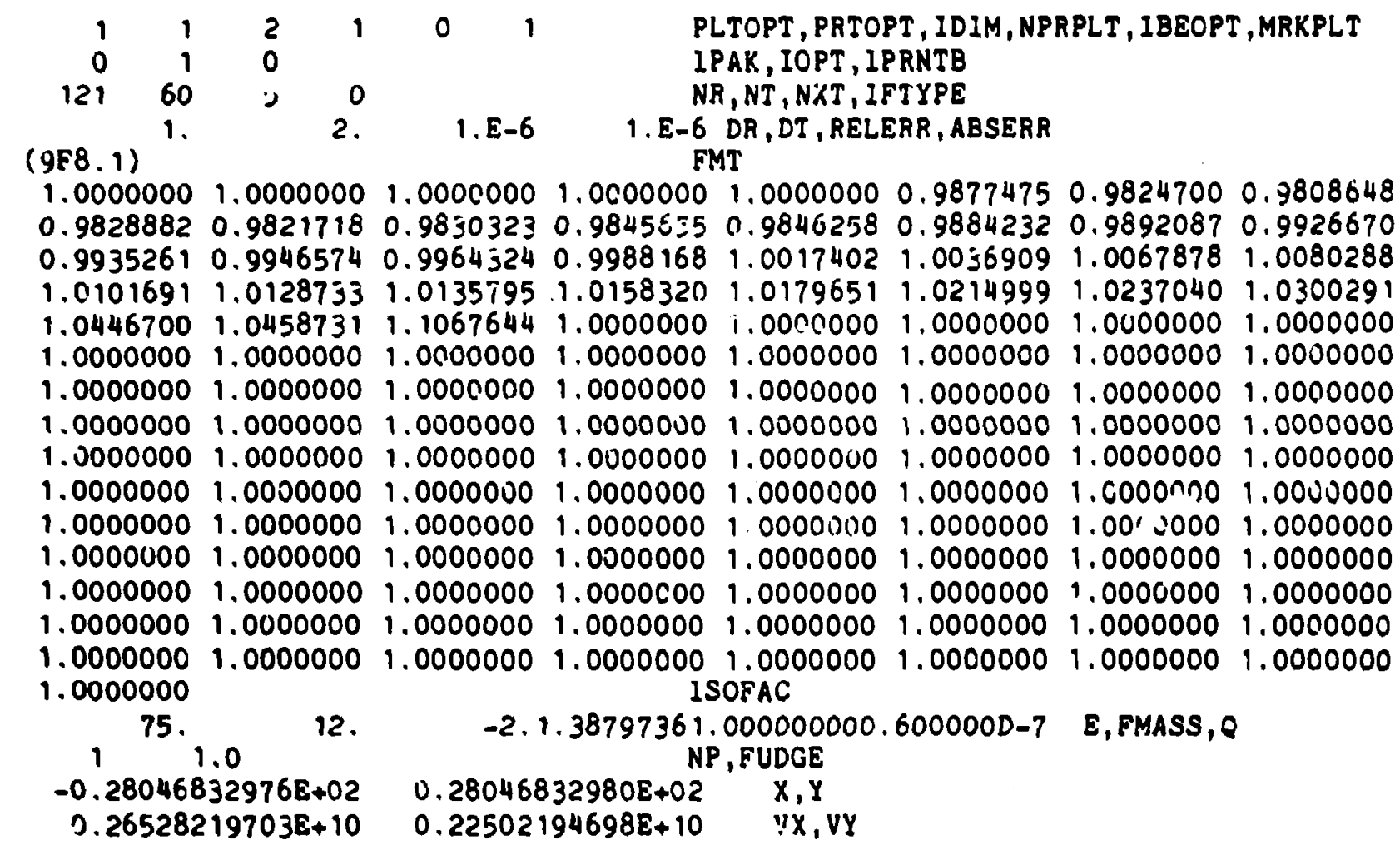

Fig. 8.1. INPUT DATA SET FOR SINGLE PARTICLE INJECTION 


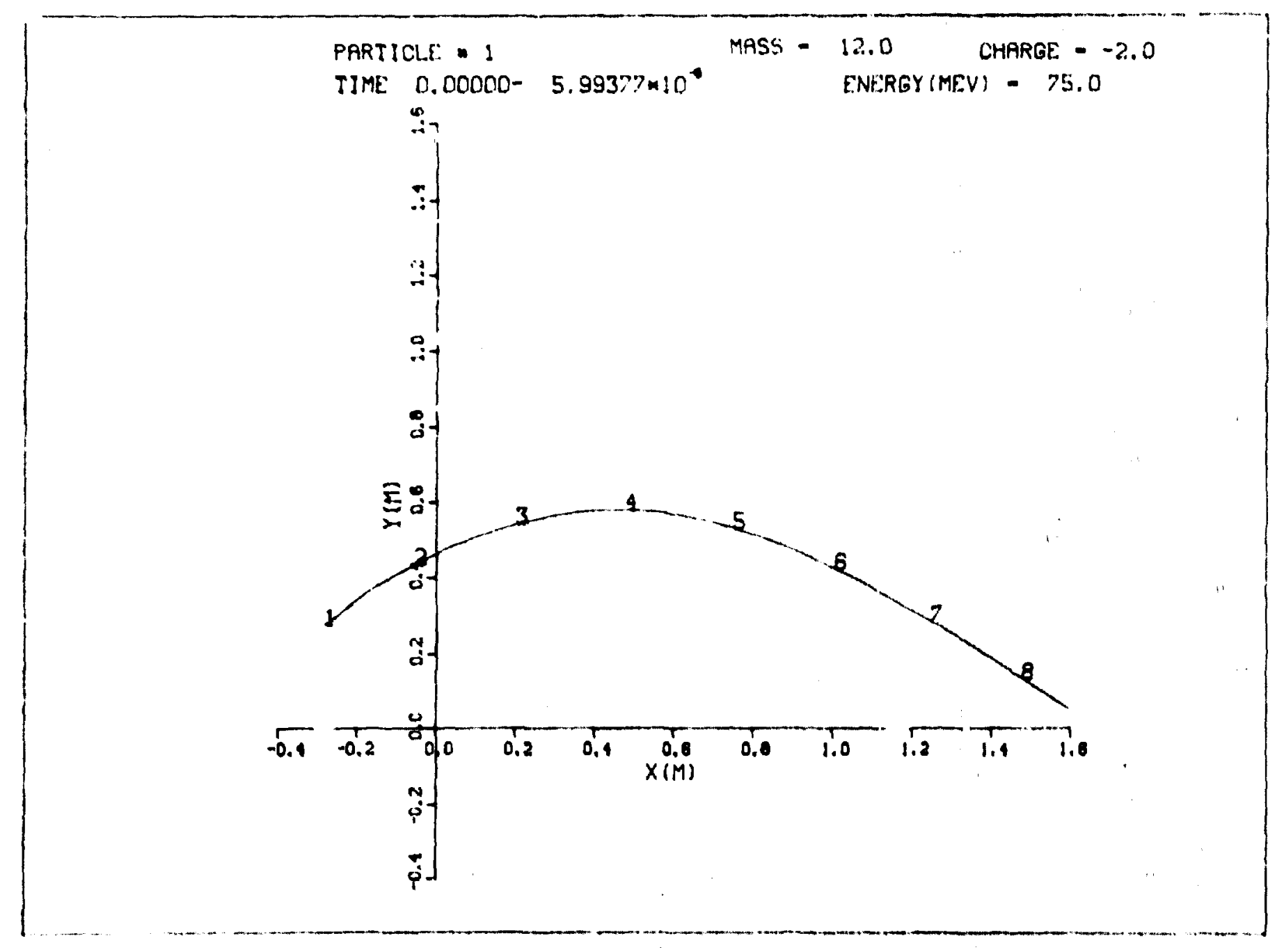

F1g. 8.2. SINGLE PARTICLE INJECTION 


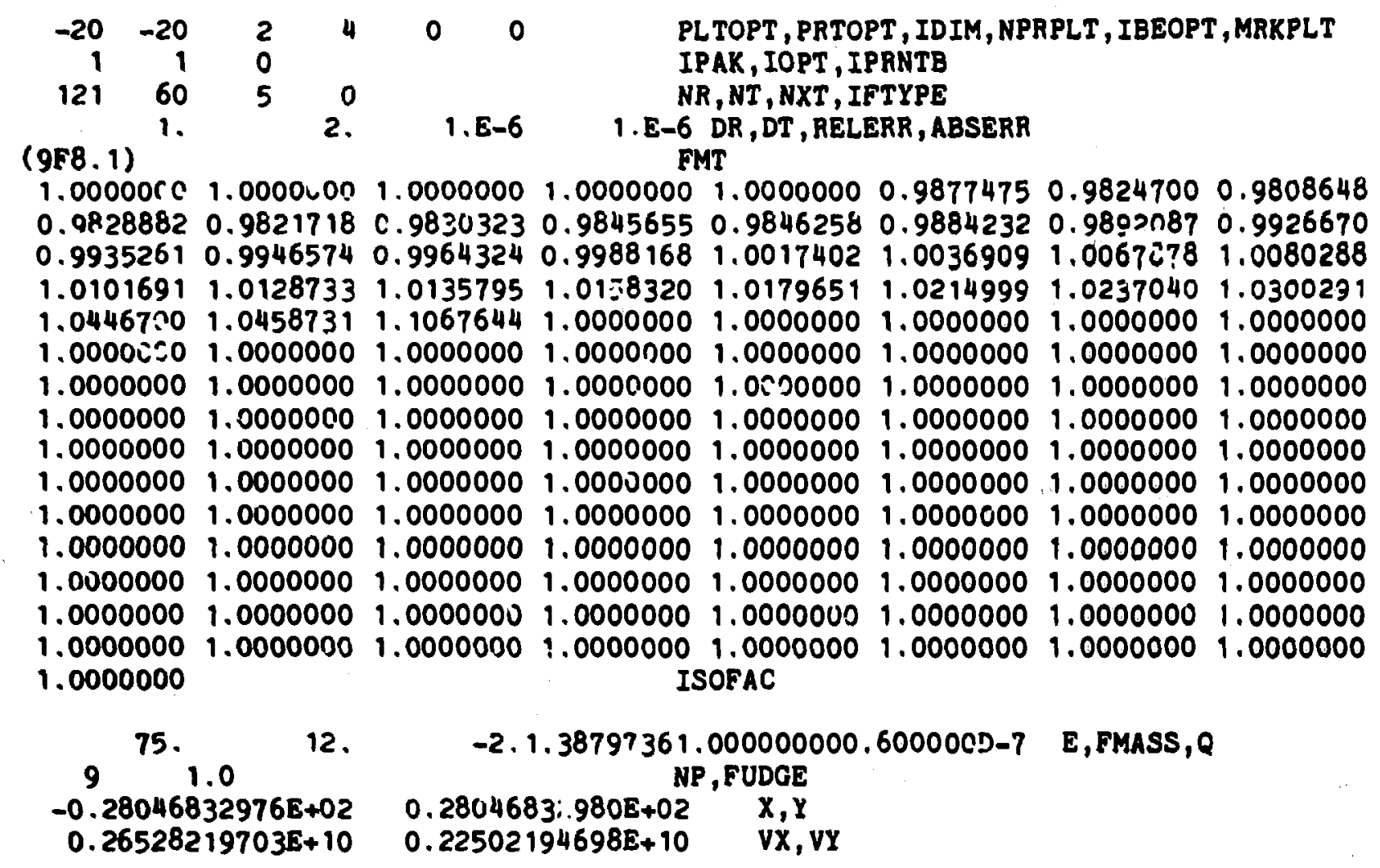

F1g. 8.3. INPUT DATÁ SET FOR NINE PARTICLE PACKET INJECTION 


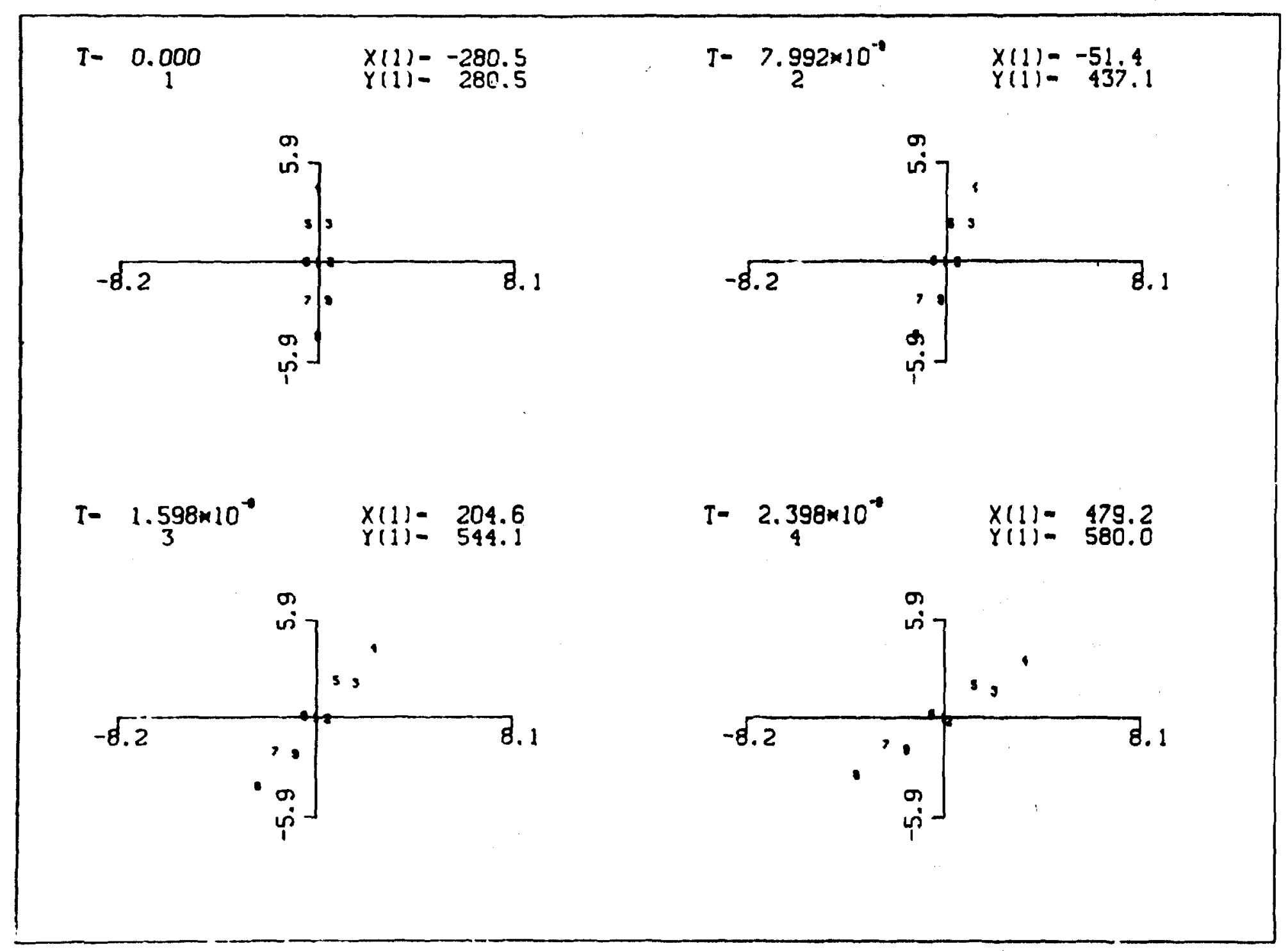

Fig. 84. NINE PARTICLE PACKET INJECTION 


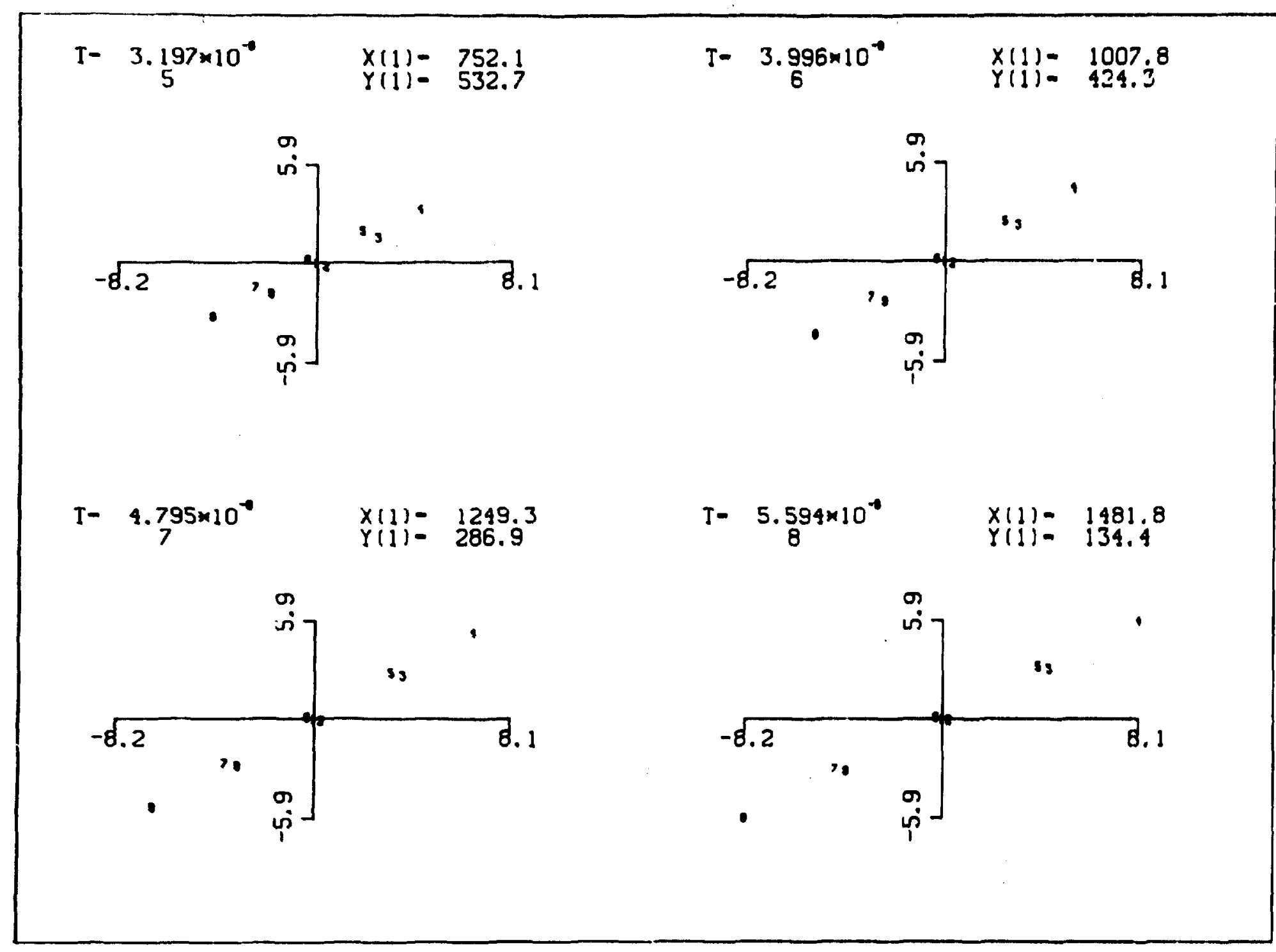

Fig. 8.4. NDNE PARTICLE PACKET INJECTION (cont.) 


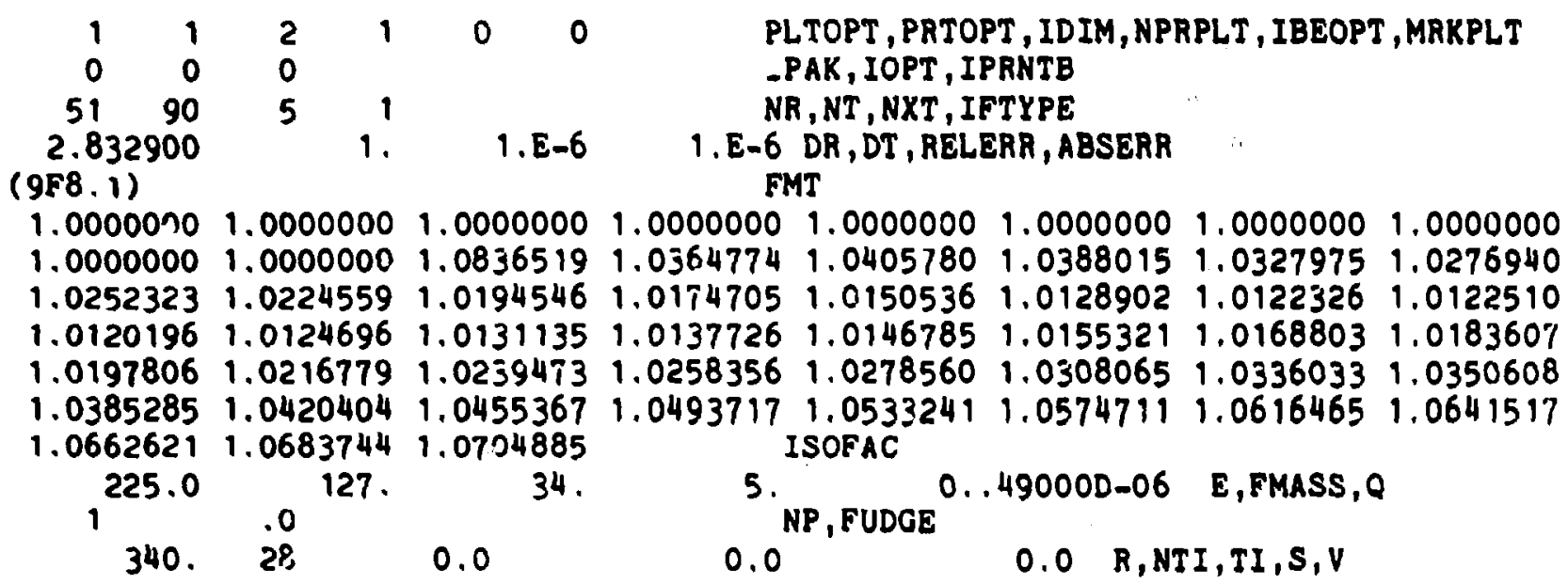

Fig. 8,5. INPUT DATA SET FOR PRECESSIONAL INJECTION 


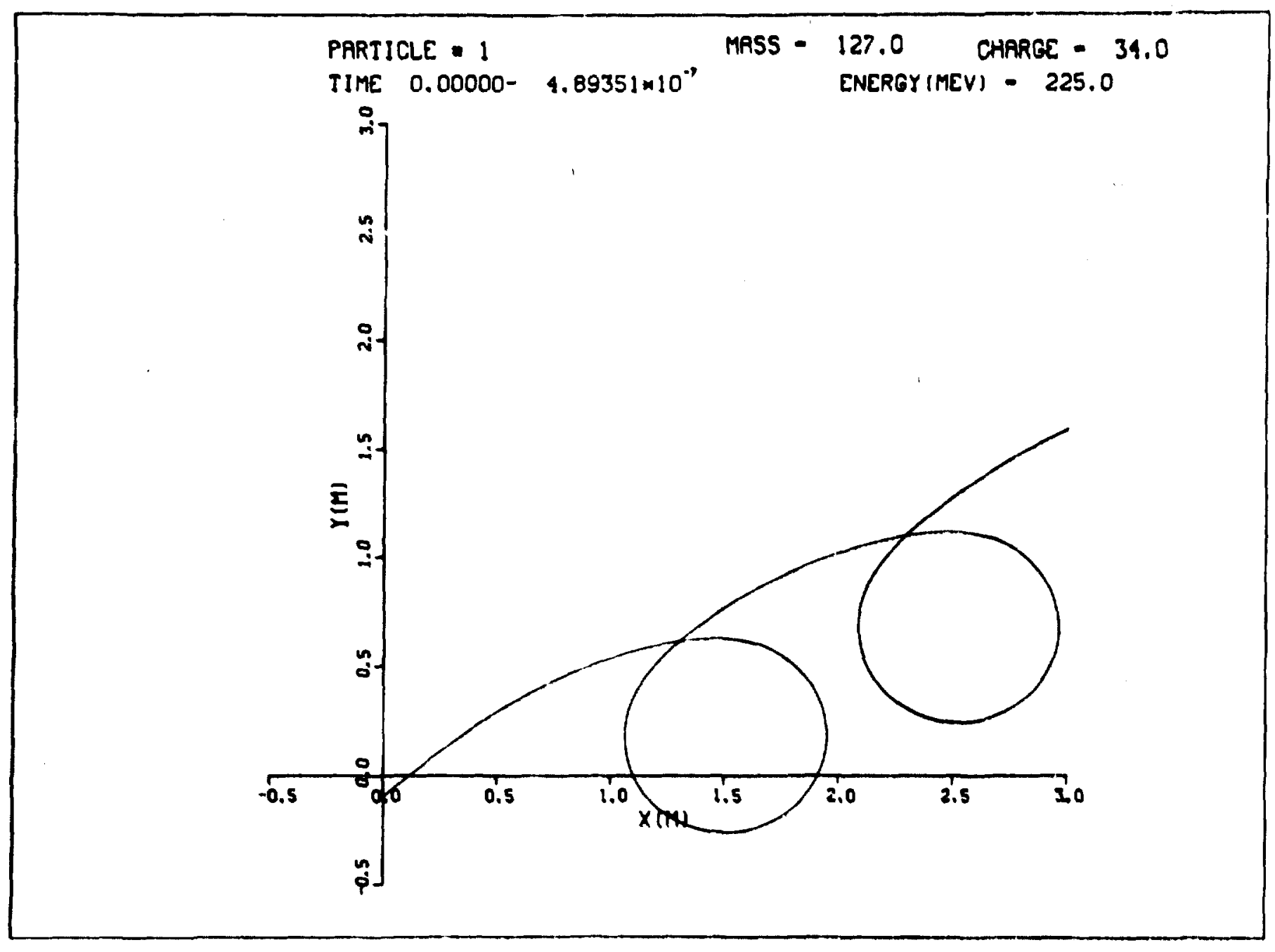

F18. 8.6. PRECESSIONAL INJECTION 


\section{UNITS INFORMATION}

All internal calculations use MSS equations of motion and metric quantities; however. quantities are input in more "usf $r$ preferred" units.

\begin{tabular}{lll}
\hline Input Variable & Input Units & Intemal Units \\
\hline B & gauss & negative tes.la \\
BEG & seconds & seconds \\
DR & inches & meters \\
DT & degrees & radians \\
E & MeV & joules \\
END & seconds & jeconds \\
FMASS & amu & kilograms \\
NTI & degrees & radians \\
PSPACF & millimeters & milifmeters \\
PWIDTH & mm-mrad & mm-mrad \\
Q & electron units & Coulombs \\
R & cm & meters \\
S & cm & meters \\
STPSIZ & cm & meters \\
TI & degrees & radians \\
TINT & seconds & seconds \\
TMAX & seconds & seconds \\
V & cm/sec & meters/sec \\
\hline & & \\
\hline
\end{tabular}


APPENDIX h

Inice-beam properties may be studied by following the trajectories of a group of particles which outline the perimeter of an appropriate volume of phase sface. Such a group of particles is shown in Fig. A.:, and is referred tc is a "packet". Particle I" defines the center of the beam, and the remaining, eight particles are distributed in the transverse-plane to particle 1 in either spatial or angular displacement.

Since the initial conditions differ for the particles in the packet, at some later time $T \neq T_{i}$, the particles will no longer 1 ie on the cransverse-plane to particle 1, but will appear as in Fig. A.2. (Note that the displacoment from the transverse-plane is exaggerated for clarity.) In order in display the transverse-plane phase space packet, particles 2 through 9 must be transformed to the transverse-plane. This is accomplished by assuming the magnetic field to be constant within the volume of the packet, which implies the particles follow circular trajectories to the transverse-plane, as indicated in Fig. A.2. 



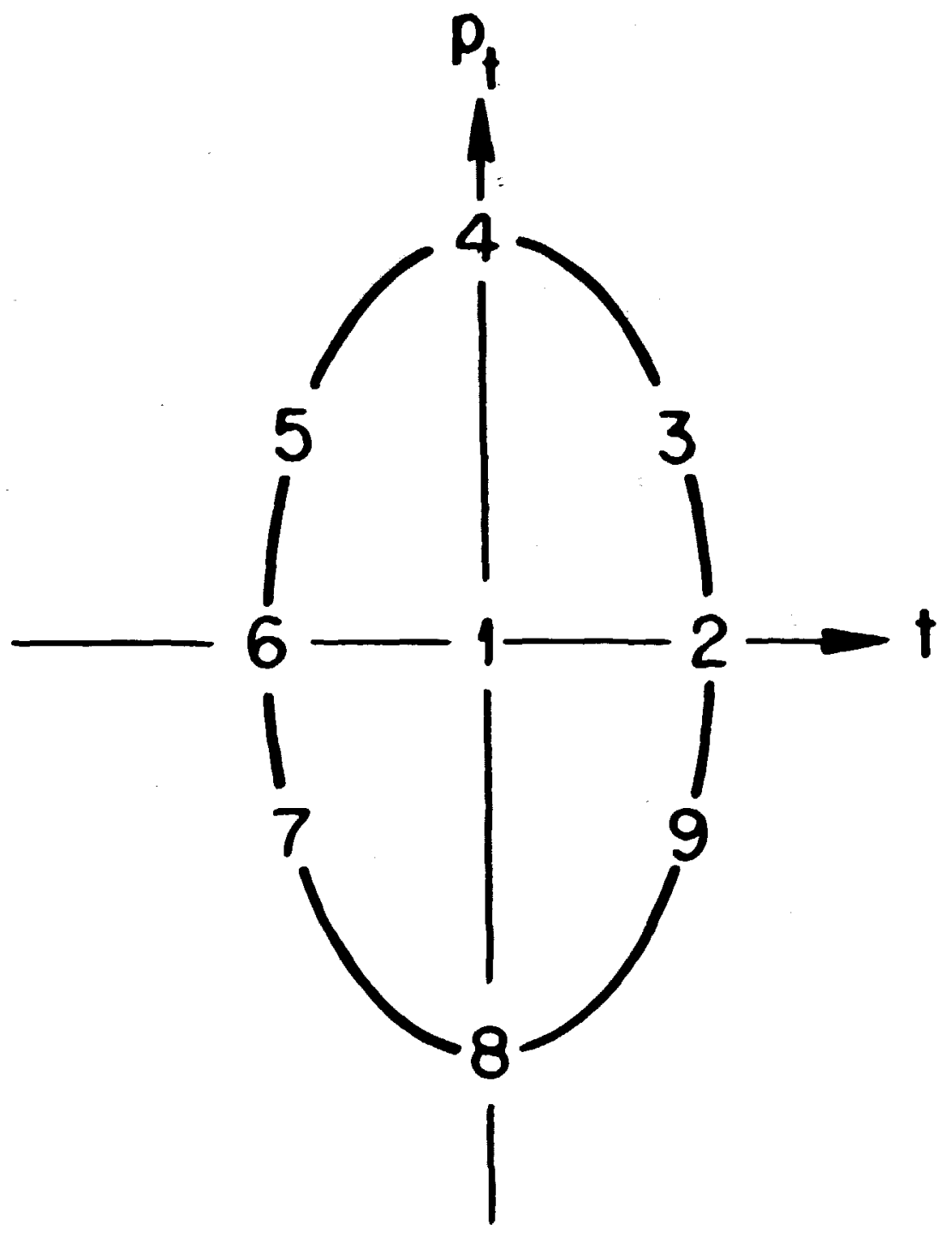

P1g. A.1. PHASE SPACE PACKET 


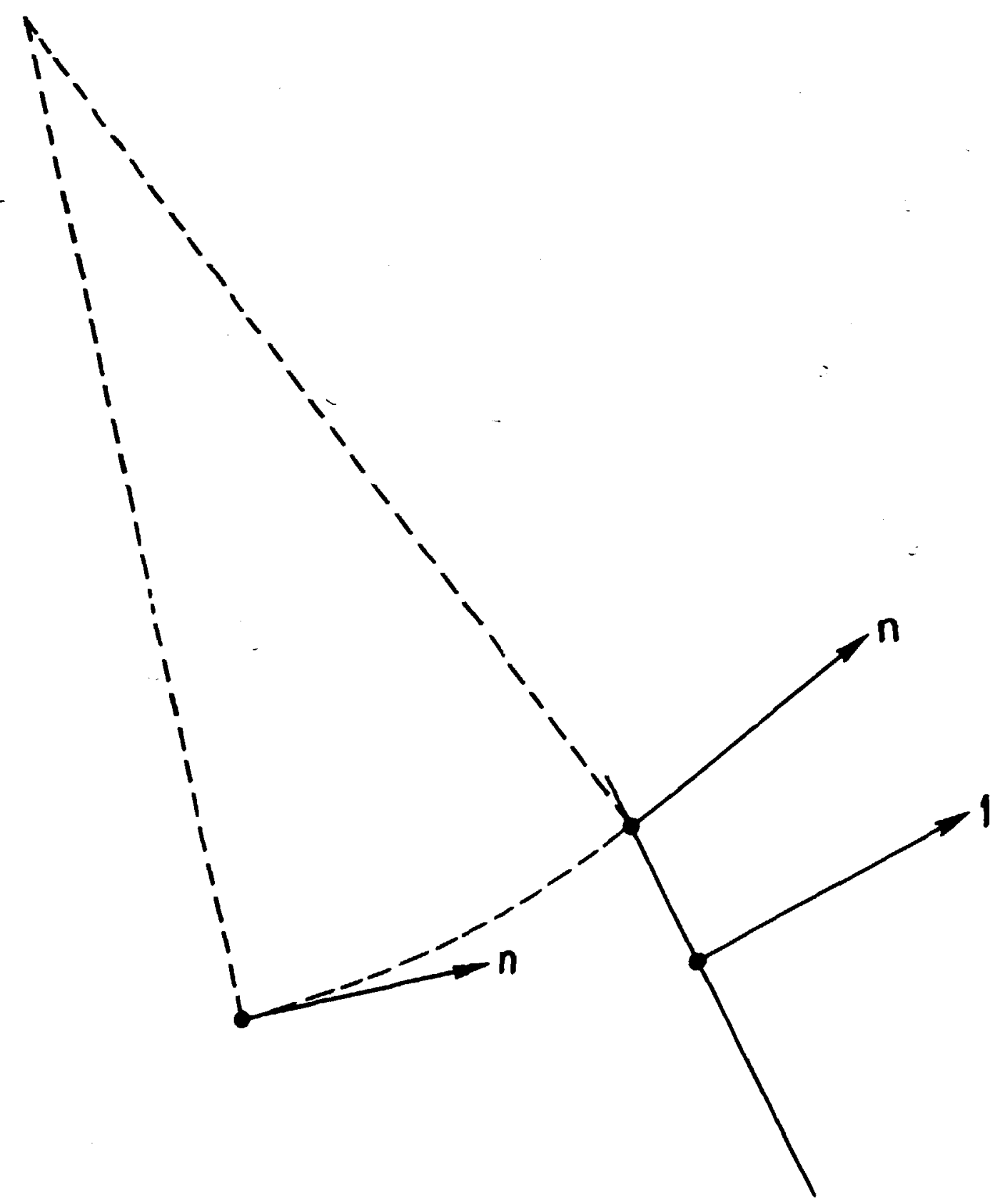

FIR. A.2. TRANSFORHATION TO TRANSVERSE PIANF. 
REFERENCES

1. For a definition of a packet, see GIP: An Interactive General Orbit Code Input Program, ORNL/CSD/TM-14 (1976).

2. DISSPLA is a software plotting package (Integrated Software Systeas Corp.) locally implemented on the IEY-360's and the PDP-10. Documentation is avallable frow the Computer Sciences Division librarian at ORAL.

3. QHKPOP is a DISSPLA program. See plotting procedure for brief description of its use.

4. COC is docunented in ORN/CSD/TM-53 (1979).

5. L. F. Shampine and M. K. Gordon, Computer Solution of Ordinary Differential Equations, $W$. H. Freeman and Co., San Francisco, (1975).

6. G. H. Westley and J. A. Watts, Editors, The Computing Technol sgy Center Numerical Analysis Library. CrC-39, (1970).

7. H. A. van Kampen and J. Liedorp, "Precession Injection in the Delft Isochronous Cyclotron," in Proceedings of the Seventh International Conference on Cyclolrons and their Applications, Birkhäuser Verlag, Basel and Stuttgart (1975), p. 254 . 


\section{ORNL/CSD/TM-94}

INTERNAL DISTRIBUTION

1. P. A. Arcuri
2. D. B. Ball
3. J. D. Bell
4. H. P. Carter/A. A. Brooks/
CSD X-10 Library
5. B. J. Casstevens
6. T. P. Cleary
7. R. L. Ferguson
8. R. .. Fisiher
9. E. D. Hudson
10. R. S. Lord
11. C. A. Ludemann

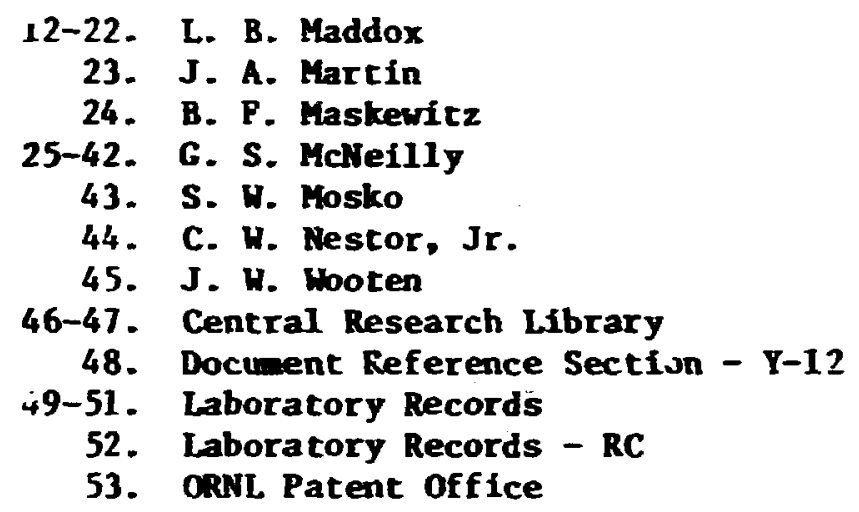

EXTERNAL DISTRIBUTION

54. J. W. Beal, General Atomic Co., P. 0. Box 81608, San Diego, California 92138

55. H. G. Blosser, Cyclotron Laboratory, Michigan State University, East Lansing, Michigan 48824

56. A. H. Botha, NAC, C.S.I.R., P. O. Box 320, Stellenbosch 7600 , South Africa

57. Chief, Mathematics and Ceoscience Branch, DOE, Washington, DC 20545

58. D. J. Clark, Lawrence Berkeley Laboratory, Berkeley, California 94720

59. J. S. Colonias, Lawrence Berkeley Laboratory, Berkeley, California 94720

50. R. H. Davis, Physics Department, Florida State University, Tallahassee, Flor Ida 32306

61. J. D. Fox, Physics Department, Florida State University, Tallahassee, Florida 32306

62. M. M. Gordon, Cyclotron Laboratory, Michigan State University, East Lansing, Michigan 48824

63. G. E. Guest, Genaral Atomíc Co., P. O. Box 81608, San Diego, Cal ifornia $\$ 2138$

64. E. A. Heighway, Chalk River Nuclear Laboratorles, Chalk River, Ontario, Canada

65. W. Joho, S.I.N., 5234 Villigen, Switzerland

66. J. M. Loiseaux, I.S.N., University de Grenoble, B.P. No. 257, Centre de Tri, 38044 Grenoble CEDEX, France

67. T. T. Luong, GANIL, I.P.N., B.P. No. 1, 91406 Orsay, France

68. G. H. Mackenzie Tri-University Meson Pacility, University of British Columbia, Vancouver 8, B. C., Canada

69. M. I. Mallory, Cyclotron Laboratory, Michigan State Univeratty, East Lansing, Michigan 48824

70. T. Nomura, Institute of Physical and Chemical Research, Wako-Shi, Saitama 351, Japan 
71. J. H. Ornrod, Chalk River Nuclear Laboratories, Chalk River, Ortario, Canada

72. Office of Assistant Manager for Energy Research and Development, DOE/ORO, P. O. Box E, Dak Ridge, Tennessee 37830

73. J. M. Rogers, Division 8324, Sandia Laboratories, P. O. Box 969, Livernore, California 94550

74-100. Tecimical Inforeation Center, U.S. Departent of Energy, Oak Ridge, Tennessee 37830 